\title{
Loss of cAMP-Dependent Protein Kinase A Affects Multiple Traits Important for Root Pathogenesis by Fusarium oxysporum
}

\author{
Hye-Seon Kim, ${ }^{1}$ Sook-Young Park, ${ }^{1}$ Sangwoo Lee, ${ }^{1}$ Elizabeth L. Adams, ${ }^{2,3}$ Kirk Czymmek, ${ }^{2,3}$ and \\ Seogchan Kang ${ }^{1}$ \\ ${ }^{1}$ Department of Plant Pathology, The Pennsylvania State University, University Park16802 U.S.A.; ${ }^{2}$ Delaware Biotechnology \\ Institute, Newark, DE 19711 U.S.A.; ${ }^{3}$ Department of Biological Sciences, University of Delaware, Newark, DE 19716 U.S.A.
}

Submitted 18 November 2010. Accepted 14 January 2011.

\begin{abstract}
The soilborne fungal pathogen Fusarium oxysporum causes vascular wilt and root rot diseases in many plant species. We investigated the role of cyclic AMP-dependent protein kinase A of $F$. oxysporum (FoCPKA) in growth, morphology, and root attachment, penetration, and pathogenesis in Arabidopsis thaliana. Affinity of spore attachment to root surfaces of $A$. thaliana, observed microscopically and measured by atomic force microscopy, was reduced by a loss-offunction mutation in the gene encoding the catalytic subunit of FoCPKA. The resulting mutants also failed to penetrate into the vascular system of $A$. thaliana roots and lost virulence. Even when the mutants managed to enter the vascular system via physically wounded roots, the degree of vascular colonization was significantly lower than that of the corresponding wild-type strain $0-685$ and no noticeable disease symptoms were observed. The mutants also had reduced vegetative growth and spore production, and their hyphal growth patterns were distinct from those of $\mathrm{O}$ 685. Coinoculation of O-685 with an focpkA mutant or a strain nonpathogenic to $A$. thaliana significantly reduced disease severity and the degree of root colonization by $\mathrm{O}$ 685. Several experimental tools useful for studying mechanisms of fungal root pathogenesis are also introduced.
\end{abstract}

Fungal pathogens typically undergo a series of cellular and developmental changes during host colonization in response to various extracellular stimuli, such as physical and chemical properties of the plant surface and intra- and intercellular spaces, and environmental conditions (e.g., nutrient and water availability and temperature). Therefore, successful host colonization, depends on the pathogens' ability to process and integrate such diverse stimuli in order to execute appropriate cellular and developmental changes. A number of well-conserved genes that are involved in controlling such changes have been identified in fungi and include heterotrimeric $G$ proteins (Bölker 1998; Delgado-Jarana et al. 2005; Jain et al. 2003, 2005; Li et al. 2007; Mehrabi et al. 2009; Shimizu and Keller 2001; Yu et al. 2008), and components of the cyclic AMP (cAMP)-mediated signaling pathway (Adachi and Hamer 1998; Borges-Walmsley and Walmsley 2000; Brakhagea and

Corresponding author: Seogchan Kang; E-mail: sxk55@psu.edu; Telephone: +1.814 .863 .3846 ; Fax: +1.814.863.7217.

* The $e$-Xtra logo stands for "electronic extra" and indicates that eight supplementary figures are published online.
Liebmanna 2005; Choi and Xu 2010; D'Souza and Heitman 2001; Fillinger et al. 2002; Kronstad et al. 1998; Lengeler et al. 2000; Liebmann et al. 2003, 2004; Rocha et al. 2001) and the signaling pathway involving mitogen-activated protein kinases (MAPK) (Chen and Thorner 2007; Di Pietro et al. 2001; Gerits et al. 2008; Martínez-Espinoza et al. 2004; Mey et al. 2002; Ruiz-Roldán et al. 2001; Su and Karin 1996; Thines et al. 2000; Wang et al. 2009; Xu and Hamer 1996; Yamauchi et al. 2004; Zhao et al. 2005).

In fungi, the cAMP-mediated signaling pathway has been shown to be involved in diverse processes, including nutrient sensing, stress response, regulation of metabolism, development, and pathogenicity. This pathway is required for proper growth and differentiation of Saccharomyces cerevisiae (Baroni et al. 1994; Kraakman et al. 1999; Nazarko et al. 2008; Pan and Heitman 1999; Tamaki 2007; Thevelein et al. 2000; Tokiwa et al. 1994). In Schizosaccharomyces pombe, the pathway regulates sexual development (Maeda et al. 1994). Mutants of $S$. pombe with nonfunctional adenylyl cyclase, an enzyme that catalyzes the conversion of ATP to cAMP, or defective catalytic subunit of cAMP-dependent protein kinase A (CPKA), exhibited conidial conjugation and sporulation even under nonstarvation conditions (Hatanaka and Shimoda 2001; Yu et al. 1994). In Neurospora crassa, this pathway has been shown to control hyphal tip growth, conidiation, and carbon metabolism (Banno et al. 2005; Bruno et al. 1996; Freitas et al. 2010; Ivey et al. 1999; Kays et al. 2000; Kore-Eda et al. 1991; Yang and Borkovich 1999). In the corn pathogen Ustilago maydis, the pathway is involved in pheromone responses, pathogenesis, morphogenesis, and gall formation (Dürrenberger et al. 1998; Gold et al. 1994; Gold et al. 1997; Kahmann et al. 1999; Krüger et al. 1998; Lee et al. 2003; Martínez-Espinoza et al. 2004; Müller et al. 2004; Ramesh et al. 2001; Regenfelder et al. 1997). The cpkA mutants of Magnaporthe oryzae exhibited reduced appressorium formation and no host penetration (Adachi and Hamer 1998; Choi et al. 1998; Kang et al. 1999; Lee and Dean 1993; Mitchell and Dean 1995; Xu et al. 1997). The critical role of CPKA in pathogenesis has also been demonstrated in other plant-pathogenic fungi, including Botrytis cinerea (Doehlemann et al. 2006; Schumacher et al. 2008), Colletotrichum spp. (Dickman et al. 2007; Takano et al. 2001; Yamauchi et al. 2004; Yang and Dickman 1999), Fusarium verticillioides (Choi and Xu 2010), Mycosphaerella graminicola (Mehrabi and Kema 2006), and Verticillium dahliae (Tzima et al. 2010), and human- or animal-pathogenic fungi such as Aspergillus fumigatus (Brakhagea and Liebmanna 2005; Grosse et al. 2008; Liebmann et al. 2003, 2004; Oliver 
et al. 2002), Candida albicans (Bockmühl et al. 2001; Cloutier et al. 2003), and Cryptococcus neoformans (D'Souza et al. 2001; Hicks et al. 2004; Pukkila-Worley and Alspaugh 2004).

The cAMP-mediated signaling pathway is intimately connected to the signaling pathways involving G-proteins and MAPK (Gerits et al. 2008; Kronstad et al. 1998; Lafon et al. 2006; Maidan et al. 2005; Sengupta et al. 2007; Shimizu and Keller 2001; Stork and Schmitt 2002; Xu and Hamer 1996). The G protein-coupled receptors (GPCR) sense various extracellular signals. These external signals cause the dissociation of $\mathrm{G} \beta \mathrm{G} \gamma$ from $\mathrm{G} \alpha$ which, in turn, activates adenylyl cyclase. Association of cAMP with the regulatory subunits of CPKA dissociates them from the catalytic subunits, resulting in the activation of the enzyme (Johnson et al. 1996; Taylor et al. 1999, 2010). The crosstalk between the cAMP and MAPK signaling pathways regulates pseudohyphal differentiation in Saccharomyces cerevisiae (Borges-Walmsley and Walmsley 2000; Kronstad et al. 1998; Lengeler et al. 2000; Sengupta et al. 2007). In M. oryzae, both the cAMP (Xu and Hamer 1996) and MAPK (Thines et al. 2000; Xu and Hamer 1996; Zhao et al. 2005) signaling pathways play critical roles in appressorium formation and in planta ramification.

In this study, we characterized the role of $F$. oxysporum CPKA in growth and root pathogenesis. Pathogenic members of this cosmopolitan fungal species complex cause vascular wilt, damping-off, and root rot diseases in many plant species (Di Pietro et al. 2001; O'Donnell et al. 2009). The fungus typically invades the xylem system of host plants, leading to the disruption of vascular function (Di Pietro et al. 2001). Unlike foliar pathogens that undergo conspicuous, readily visible pathogenesis processes, disease progression by soilborne pathogens such as $F$. oxysporum is concealed within the soil, making it difficult to study pathogenesis mechanisms. Use of cytological tools in combination with multiple platforms for growing and infecting Arabidopsis thaliana helped us investigate how CPKA in F. oxysporum (named FoCPKA) contributes to root colonization and pathogenesis. Atomic force microscopy (AFM) was used to quantify the effect of FoCPKA mutation in spore attachment to the root surface and to image the surface topography of spores.

\section{RESULTS}

\section{Mutagenesis of FoCPKA, a gene encoding}

the catalytic subunit of CPKA in $F$. oxysporum.

The FoCPKA gene was cloned from F. oxysporum O-685, a cabbage isolate pathogenic to A. thaliana (Czymmek et al. 2007; Ospina-Giraldo et al. 2003). The gene contains a 1,716bp open reading frame (ORF) with three introns $(56,56$, and $51 \mathrm{bp}$, respectively) and encodes a protein of 572 amino acids. The predicted protein exhibited a high degree of identity to previously characterized fungal CPKA (e.g., Gibberella zeae, 98\%; M. oryzae, 95\%; and N. crassa, 95\%). To facilitate microscopic studies of the role of FoCPKA in root pathogenesis, we first generated O-685 expressing green and red fluorescent proteins (Supplementary Fig. 1) via Agrobacterium tumefaciens-mediated transformation (ATMT). Resulting transformants were first screened for strong constitutive fluorescence and subsequently for growth and pathogenicity to confirm that ATMT had not affected these traits. Two transformants, one expressing green fluorescent protein (labeled O-685G) and the other expressing red fluorescent protein (labeled O-685R), were employed for subsequent analyses. A mutant allele of FoCPKA was cloned in pGKO1, a binary vector developed for efficient gene disruption (Khang et al. 2005), and was introduced into O-685R via ATMT, resulting in gene disruption mutants.

\section{Disruption of FoCPKA affected multiple growth-related characteristics.}

Growth characteristics of a mutant (CM14-2) on three different solid media, including complete medium (CM), minimal medium (MM), and potato dextrose (PD), were compared with those of O-685, O-685G, O-685R, and an ectopic transformant (CM1-1). Colony diameters of O-685, O-685G, O-685R, and CM1-1 on all three media were not significantly different after 6 days of growth (Supplementary Fig. 2). In contrast, CM14-2 exhibited 30 to $40 \%$ reduction in radial growth relative to these wild-type (WT) strains. Strain CM14-2 also produced fewer conidiophores and aerial hyphae than the WT strains. Upon culturing in liquid CM, MM, and PD for 14 days, the number of microconidia produced by CM14-2 was significantly lower than that of $\mathrm{O}-685 \mathrm{G}$.

Conidia of O-685G and CM14-2 inoculated in liquid CM, $\mathrm{MM}$, and PD were observed microscopically at multiple time points, which revealed differences in germ tube growth, septation, and hyphal branching. The differences were most pronounced in PD. At $6 \mathrm{~h}$ postinoculation (hpi), conidia of these strains were indistinguishable (Fig. $1 \mathrm{~A}$ and B). However, at 15 hpi, conidia of O-685G appeared swelled and often germinated at more than one site, and their germ tubes looked bulbous (Fig. 1C). In contrast, the size of CM14-2 conidia remained the same, and a single slim and slightly curved germ tube emerged (Fig. 1D). The diameter of the germ tubes of $\mathrm{O}-685 \mathrm{G}$ was thicker than that of CM14-2, whereas the length of the germ tubes of CM14-2 was typically longer than that of O685G. Germination started more quickly in CM14-2. However, at $18 \mathrm{hpi}$, the number of germinated conidia was indistinguishable between CM14-2 and O-685G and, ultimately, fewer conidia germinated in CM14-2 (data not shown). The germinated conidia of O-685G but not those of CM14-2 tended to aggregate. At 38 hpi (Fig. 1E and F), hyphae of O-685G showed branching, whereas hyphae of CM14-2 were rarely branched. Although the diameter of $\mathrm{O}-685 \mathrm{G}$ hyphae still appeared thicker than that of CM14-2, the difference was not as pronounced as that observed at 15 hpi. Staining of hyphae with FM4-64X fluorescent dye showed that the distance between septa in CM14-2 (Fig. 1H) was greater than that of O-685G (Fig. 1G).

\section{FoCPKA is important for multiple steps during root pathogenesis.}

Plants of A. thaliana ecotype Cvi-0, which is highly susceptible to O-685 (Czymmek et al. 2007; Ospina-Giraldo et al. 2003), were inoculated with CM14-2 and two WT strains to compare their virulence. First, 2-week-old plants grown in soil were inoculated with spores $\left(0.5 \mathrm{ml}\right.$ of a $1 \times 10^{6}$ conidia $/ \mathrm{ml}$ suspension per plant) of CM14-2, an ectopic transformant (CM1-1), and O-685G as previously described (Ospina-Giraldo et al. 2003). Both O-685G and CM1-1 caused yellowing of the vascular veins of leaves 7 to 10 days postinoculation (dpi). The disease severity steadily increased and caused eventual death of most plants by 15 dpi (Fig. 2A). In contrast, plants inoculated with CM14-2 did not produce any visible symptoms during the same period, suggesting that FoCPKA is required for pathogenicity in A. thaliana.

Two additional infection methods were used to facilitate cytological analyses of the nature of pathogenicity defects in CM14-2. In both a coverslip-bottomed chamber (Czymmek et al. 2007) and a hydroponic system, CM14-2 failed to cause disease symptoms (Fig. 2). After inoculating roots of the plants grown in the chamber with $\mathrm{O}-685 \mathrm{G}$ and $\mathrm{CM} 14-2$ as previously described (Czymmek et al. 2007), root colonization was monitored using a confocal microscope (Fig. 3; Supplementary Fig. 3 ). At approximately 6 to $7 \mathrm{dpi}$, the hyphae of O-685G began 
colonizing the root surface and also started producing new spores by budding. The hyphae of CM14-2 were rarely observed on the root surface and did not produce spores. Once the elongation zone of the primary and secondary roots was colonized by $\mathrm{O}-685 \mathrm{G}$, its penetration to the vascular system was observed in a day or two. The hyphae in the vascular system proliferated, with the degree of colonization by $\mathrm{O}-685 \mathrm{G}$ increasing over time (Fig. 3). In contrast, the hyphae of CM14-2 were

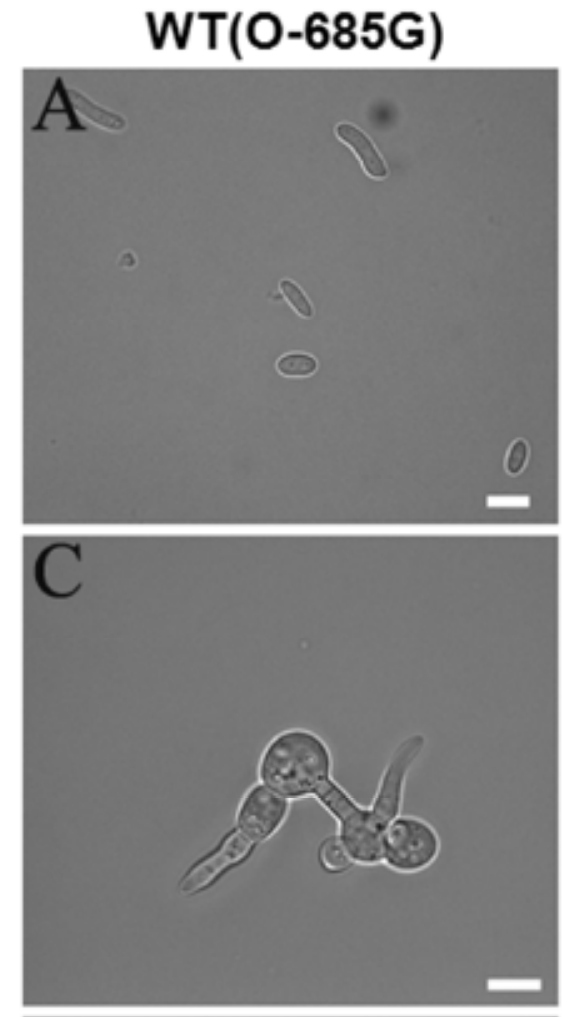

KO(CM14-2)
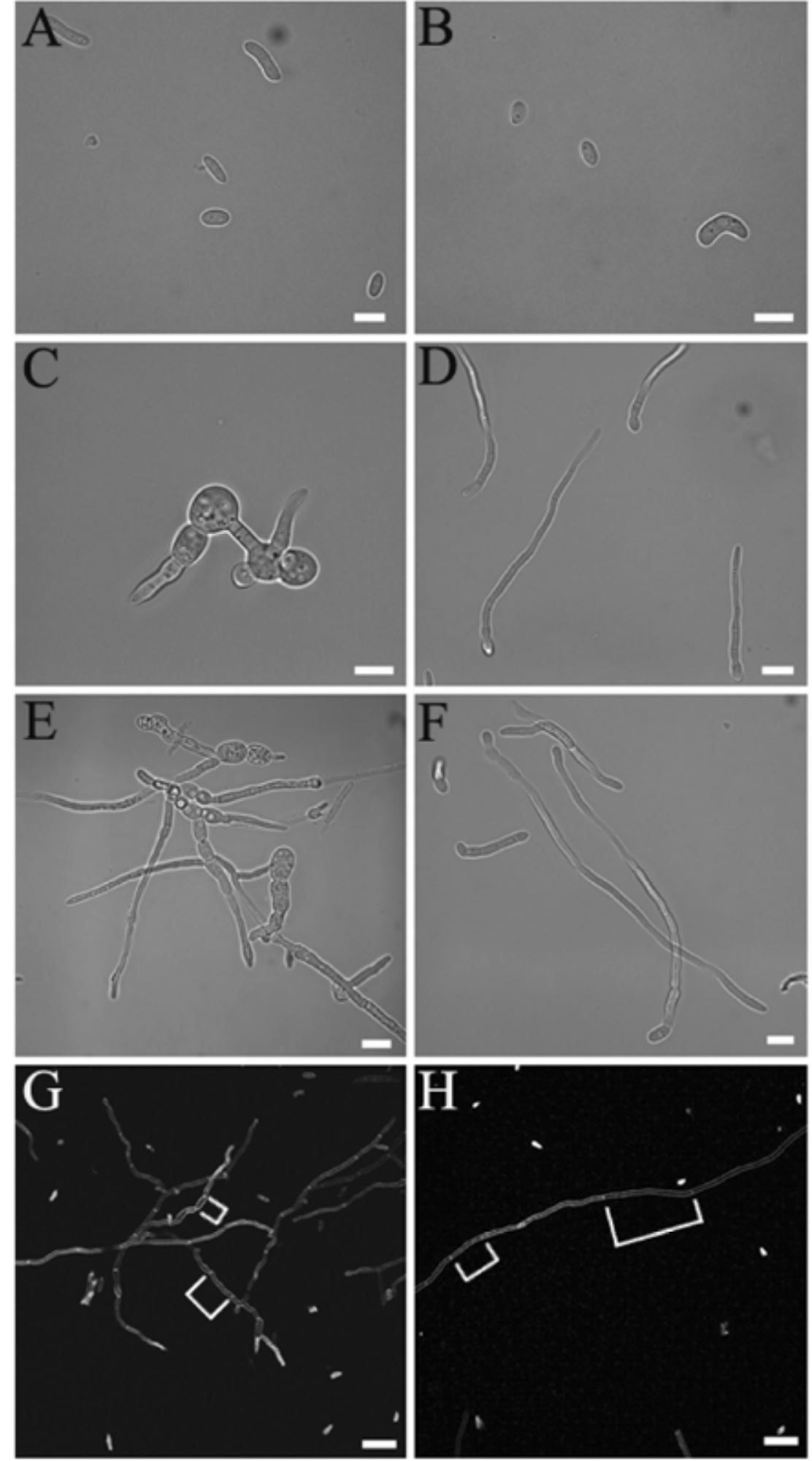

Fig. 1. Loss of cAMP-dependent protein kinase A in Fusarium oxysporum (FoCPKA) affected germination and hyphal growth. Spores of A, C, and E, O-685G and $\mathbf{B}, \mathbf{D}$, and $\mathbf{F}, \mathrm{CM} 14-2$ in potato dextrose $(\mathrm{PD})$ broth $\left(5 \times 10^{4}\right.$ conidia/ml) were incubated at $25^{\circ} \mathrm{C}$ and their germination and hyphal growth was microscopically observed at $\mathbf{A}$ and $\mathbf{B}, 6 ; \mathbf{C}$ and $\mathbf{D}, 15$; and $\mathbf{E}$ and $\mathbf{F}, 38 \mathrm{~h}$ postinoculation (hpi). $\mathbf{G}$ and $\mathbf{H}$, Hyphae growing in PD broth were stained with FM4-64X fluorescent dye and observed via confocal microscopy to determine differences in frequency of septation. Distance between septa in G, O-685G and H, CM14-2 was indicated by two brackets (shortest and longest in the field of observation). All pictures were taken at the same magnification. Scale bar $=10 \mu \mathrm{m}$. 
observed only on the root surface, with no penetration to the vascular system at both 12 and 17 dpi (Fig. 3). Even at the primordium of an emerging secondary root that had been heavily colonized by CM14-2 (Fig. 3H), optical sectioning showed that hyphae failed to grow into the vascular system.

Although the coverslip-bottomed chamber enabled detailed microscopic observations of the root colonization process by O-685G and CM14-2 without physically disrupting the infected roots, the method was not suitable for monitoring spore attachment and subsequent growth on the root surface. To compare the behavior of spores on root surfaces, 2-week-old plants of Cvi-0 that had been grown hydroponically were transferred into containers filled with Arabidopsis nutrient (AN) broth amended with spores of O-685G and CM14-2 $\left(1 \times 10^{6}\right.$ conidia/ $\mathrm{ml})$. Colonization of the root surface and the vascular system was monitored for 15 days by taking out two plants for each strain every day. At $1 \mathrm{dpi}$, spores of both strains attached mostly at the elongation zone of the primary root, lateral root cracks, root hairs, and the upper two-thirds of the primary root; however, a few spores attached to the areas immediately above the primary root tip. Although the areas of spore attachment did not look different between O-685G and CM14-2, the number of spores attached differed dramatically (Supplementary Fig. 4A to D). Between 2 and 4 dpi, more spores were observed on the root surface inoculated with O-685G, and hyphal growth increased, especially around the elongation zone of the primary and secondary roots. Because some of the hyphae growing on the root surface began to sporulate, the increase in attached spores was probably caused by a combination of new spore production by the hyphae colonizing the root surface and newly
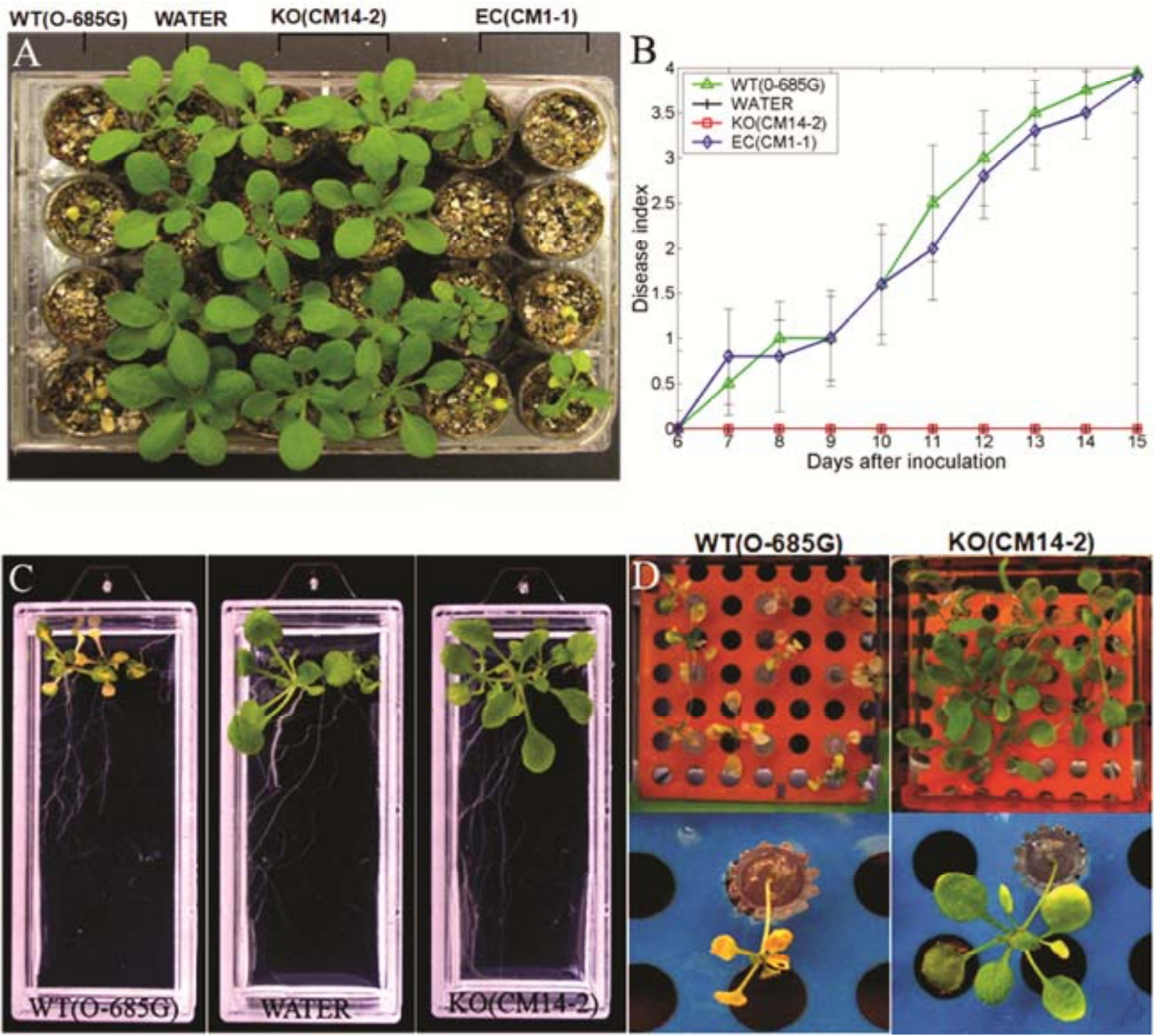

Fig. 2. FoCPKA is required for pathogenicity. Plants of Arabidopsis thaliana ecotype Cvi-0, which had been grown using three different methods, were inoculated with an focpkA mutant, CM14-2, and wild-type (WT) strains. A, Disease symptoms of plants grown using a soil mix in 24-well microtiter plate are shown 14 days postinoculation (dpi). Plants were inoculated with O-685G (first column), water (second column), focpkA mutant CM14-2 (third and fourth columns), and ectopic transformant CM1-1 (fifth and sixth columns). B, Disease progression of the plants shown in A was monitored from 6 until 15 dpi using the index ranging from 0 (healthy plant) to 4 (dead plant). Yellowing of leaf vascular tissues occurred typically within 7 to 10 dpi and gradually spread throughout the affected leaves, leading to eventual death within 15 dpi. There were no significant differences in disease severity between O-685G and CM1-1 as determined by Student's $t$ test $(P>0.05)$. Error bars indicate error of the mean derived from 12 plants for each strain (in each experiment) in two independent experiments. C, Plants of Cvi-0 grown in coverslip-bottomed chambers were inoculated with water and spores of O-685G and CM14-2 on two locations of the chamber (approximately two-thirds of the way down from the germinated seed) by injecting the spore suspension $\left(5 \mu l\right.$ of $2 \times 10^{5}$ conidia/ml per site) or water below the agar surface. Pictures were taken at $14 \mathrm{dpi}$. D, Plants of Cvi-0 that had been grown in the hydroponic system were inoculated with O$685 \mathrm{G}$ and CM14-2. Pictures were taken at $14 \mathrm{dpi}$. The bottom panel shows a zoomed-in view of a plant expressing symptoms representative of the plants observed at 14 dpi. 


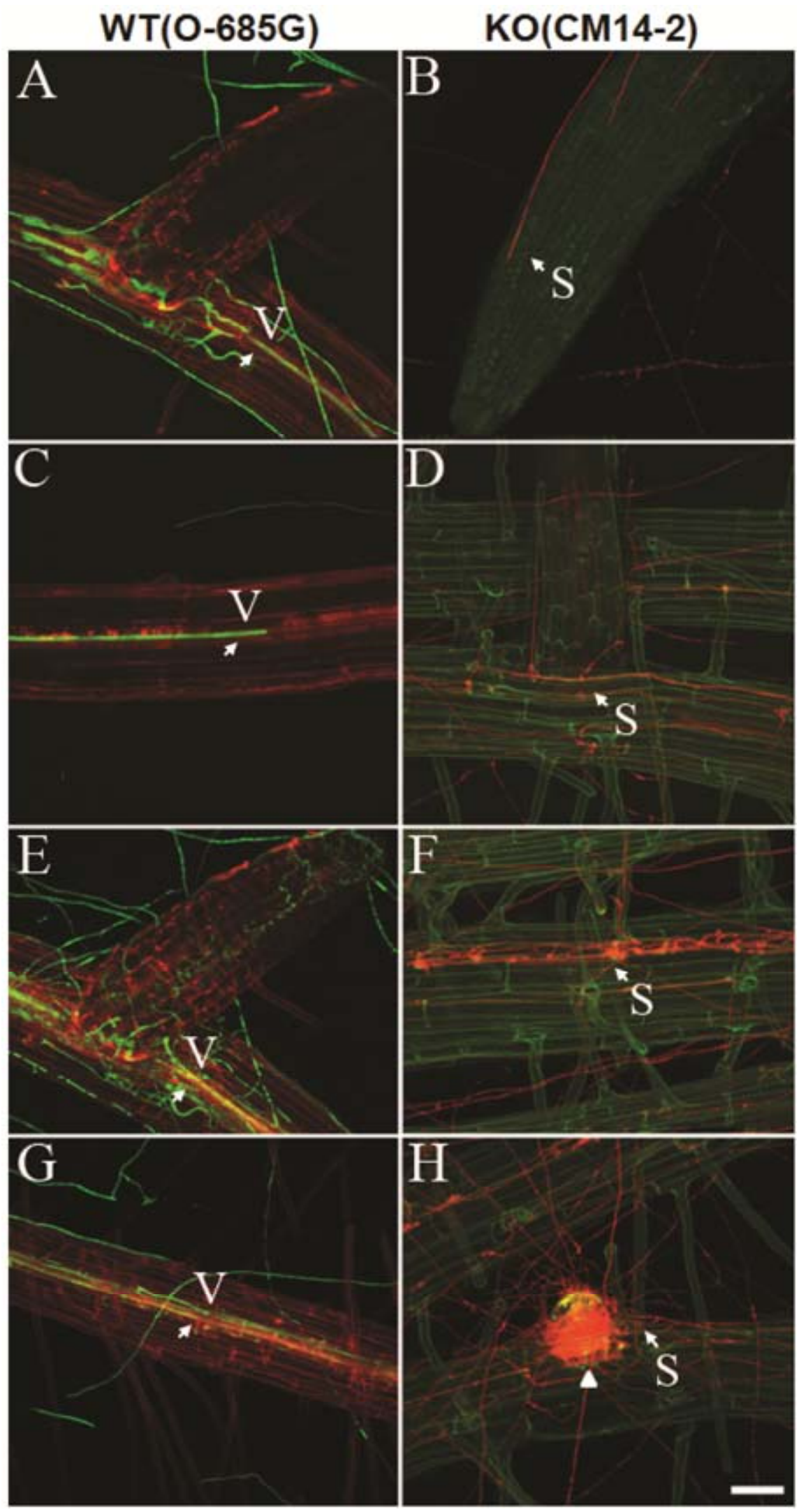

Fig. 3. FoCPKA is required for root penetration and vascular colonization. Two-week-old plants of ecotype Cvi-0 grown in coverslip-bottomed chambers were inoculated with A, C, E, and G, O-685G and B, D, F, and $\mathbf{H}$, focpkA mutant CM14-2. Root colonization by O-685G and CM14-2 documented via confocal microscopy at $\mathbf{A}$ to $\mathbf{D}, 12$ and $\mathbf{E}$ to $\mathbf{H}, 17$ days postinoculation was shown. The arrow with $\mathrm{V}$ indicates the hyphae growing through the vascular tissue. The arrow with $\mathrm{S}$ denotes the hyphae growing on the root surface. The arrowhead in $\mathrm{H}$ indicates a primordium of the secondary root that was heavily colonized by CM14-2. Scale bar $=10 \mu \mathrm{m}$. 
attached spores. The spore attachment and hyphal growth by CM14-2 remained limited. At 4 dpi, extensive hyphal networks of $\mathrm{O}-685 \mathrm{G}$ covered the root surface, with some parts of the vascular system being colonized. In contrast, the hyphal growth of CM14-2 on the root surface remained minimal, with no signs of vascular colonization. At $12 \mathrm{dpi}$, the vascular system was extensively colonized by $\mathrm{O}-685 \mathrm{G}$ whereas CM14-2 failed to do so.

We performed a spore attachment assay as previously described (Olivain and Alabouvette 1997, 1999; Recorbet and

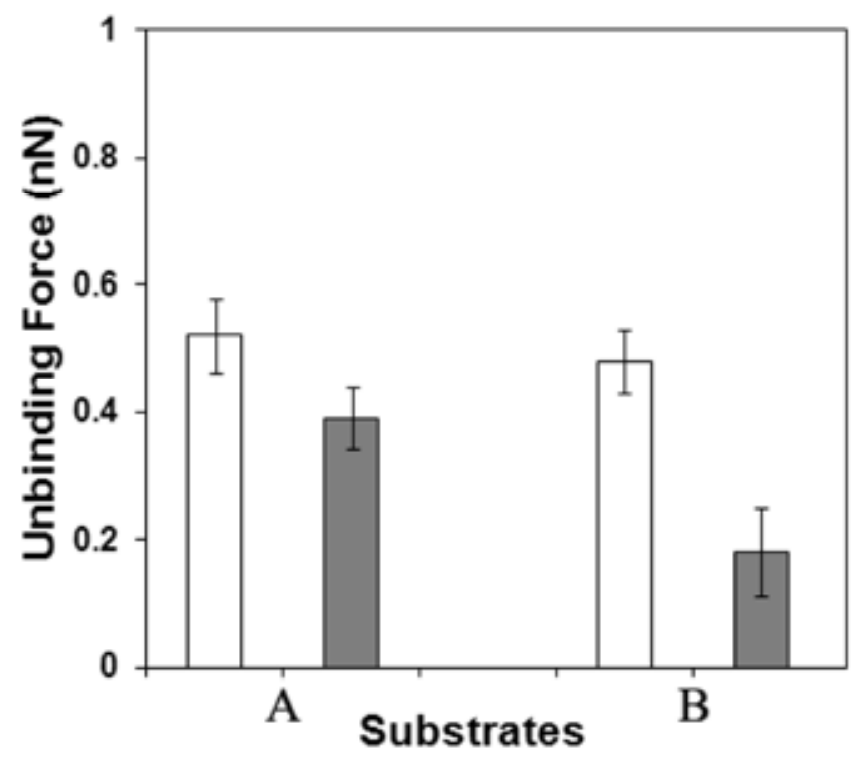

Fig. 4. Binding affinities of spores to two areas of the root surface. Twoweek old, hydroponically-grown plants of ecotype Cvi-0 were used for measuring unbinding affinities of spores from $\mathbf{A}$, the root tip and $\mathbf{B}$, the area $2 \mathrm{~cm}$ above the root tip. Atomic force microscopy tips coated with spores of O-685G and CM14-2 were used. The Y axis indicates unbinding forces measured in nano Newton. These experiments were repeated three times, on separate days, using different tips and roots to confirm the repeatability of force measurement. Error bars indicate error of the mean. There were significant differences $(P<0.001)$ in unbinding forces at both locations.
Alabouvette 1997). Roots of Cvi-0 plants dipped in spore suspension for 3 days were observed before and after vigorous shaking in sterilized water at different time points $(3,10$, and $24 \mathrm{~h}$ after shaking). A large number of $\mathrm{O}-685 \mathrm{G}$ spores was observed on the root tip before vigorous shaking, whereas the number of CM14-2 spores was minimal (Supplementary Fig. 5). After 3, 10, and $24 \mathrm{~h}$ of shaking, most O-685G spores remained attached, germinated, and grew. In contrast, almost no spores of CM14-2 were left on the root surface.

\section{Complementation of CM14-2 restored WT virulence and growth characteristics.}

To demonstrate that the phenotypes of focpkA mutants were not caused by additional mutations that had occurred during gene disruption, CM14-2 was cotransformed with a restriction fragment covering the FoCPKA gene and its flanking sequences and a plasmid that carries a gene (NAT) conferring resistance to nourseothricin. Three nourseothricin-resistant and hygromycin B-sensitive transformants were isolated. The replacement of the focpkA mutant allele with the WT gene was confirmed (Supplementary Fig. 6). Pathogenicity and growth characteristics of the complemented strains were compared with O-685R and CM14-2 as described above, which showed that the restoration of FoCPKA in CM14-2 resulted in WT phenotypes.

\section{Affinity of spore to the root surface was reduced by the disruption of $F o C P K A$.}

To compare the binding affinity of spores to the root surface quantitatively, we used AFM with spores of O-685G and CM14-2 attached to the AFM probe. The unbinding forces of single spores from the root surface at two areas, including the elongation zone of the primary root tip and the area approximately $2 \mathrm{~cm}$ above from the root tip, were measured (Fig. 4). Although fewer spores attached to the distal area than the root tip, the binding affinities of $\mathrm{O}-685 \mathrm{G}$ spores to these areas looked comparable (Fig. 4). Compared with O-685G, the binding affinities of CM14-2 spores to both areas were significantly reduced, with the reduction being more severe at the distal part of the root (Fig. 4). The surface topography of O685G and CM14-2 spores was also imaged using tappingmode AFM (Fig. 5). With the tapping mode, the tip is oscil-

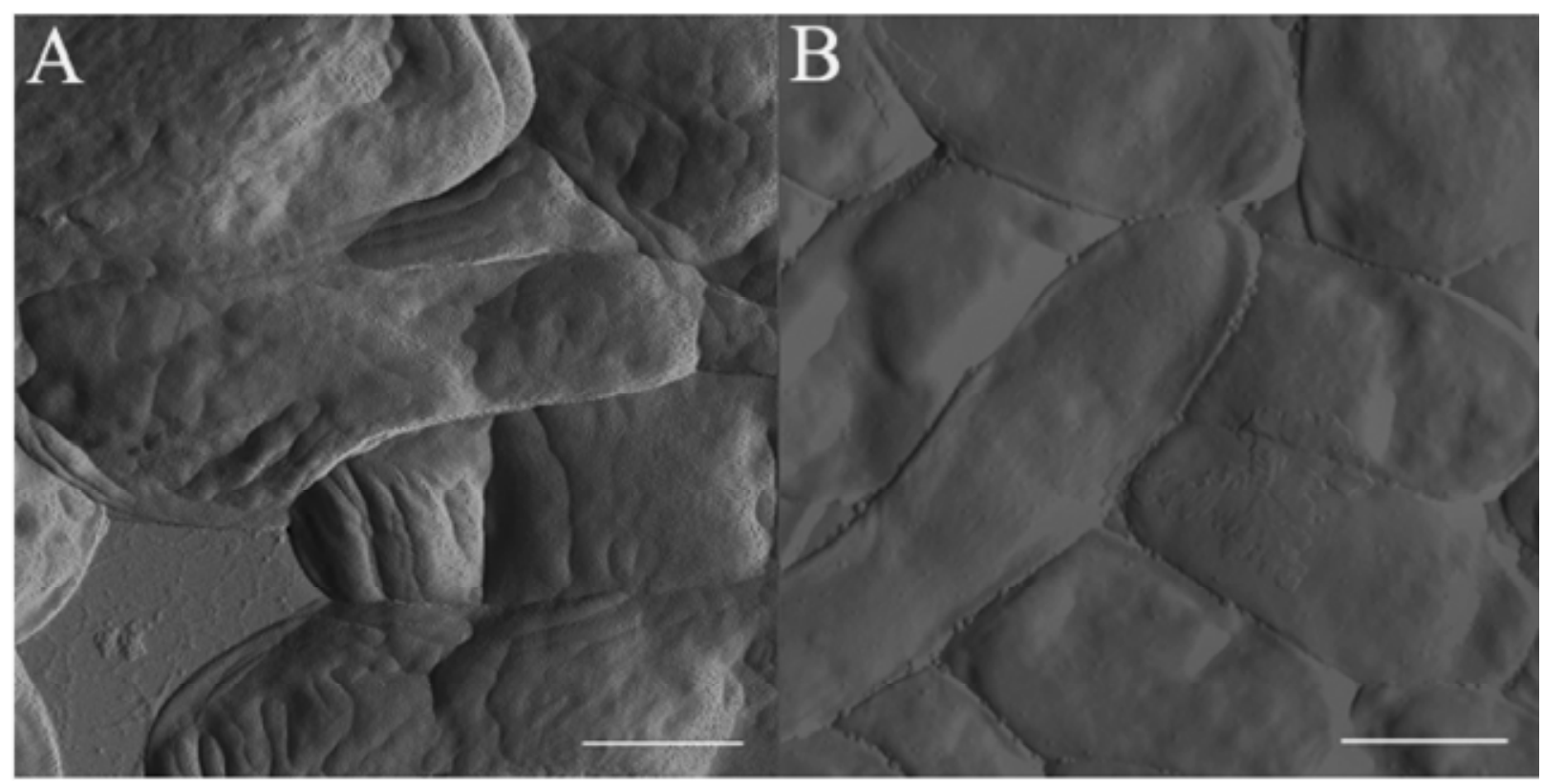

Fig. 5. Imaging of the surface topography of Fusarium oxysporum spores using atomic force microscopy. Spore surface images of A, O-685G and B, CM14-2 were created from the amplitude data channel. Scale bar $=2 \mu \mathrm{m}$. 
lated at a set frequency above the sample, resulting in very low interaction forces between the tip and the surface. As the tip tracks across the surface, the amplitude of these oscillation changes as the cantilever follows the topography of the sample. These changes in the amplitude of the oscillation can be used to generate the amplitude image and are most predominantly affected by increases and decreases in the height; as a result, these changes are highlighted in the amplitude image. This method of AFM showed that the surface of CM14-2 spores was noticeably smoother than that of $\mathrm{O}-685 \mathrm{G}$ spores (Fig. 5).

\section{CM14-2 reduced disease severity}

\section{by $0-685 G$ and promoted plant growth.}

Nonpathogenic strains of $F$. oxysporum have been evaluated as biocontrol agents against pathogenic strains of $F$. oxysporum (Freitas et al. 2010; Fuchs et al. 1997; Olivain and Alabouvette 1997, 1999). To test whether CM14-2 can protect plants from O-685G, patterns of root colonization and symptom development were recorded after inoculating hydroponically grown Cvi-0 plants with O-685G, CM14-2, and an equal mixture of these strains at two different concentrations $\left(1 \times 10^{6}\right.$ and $2 \times$ $10^{6} / \mathrm{ml}$ of spores). Although the plants infected with the mixed strains were not immune to infection, they exhibited significantly reduced disease severity compared with plants inoculated with $\mathrm{O}-685 \mathrm{G}$ alone (Fig. 6). We also tested whether a tomato isolate (FOL 4287) that is nonpathogenic to A. thaliana could protect plants from $\mathrm{O}-685 \mathrm{G}$. The plants inoculated with mixtures of FOL4287 and O-685G comparably reduced disease severity (Figs. 6 and 7).

Microscopic observations revealed that the roots inoculated with CM14-2 alone had a few spores attached to the roots but, in the presence of $\mathrm{O}-685 \mathrm{G}$, the number of CM14-2 spores attached increased. The number of $\mathrm{O}-685 \mathrm{G}$ spores attached to the roots decreased in the presence of CM14-2 spores but the degree of reduction did not appear to be caused by dilution, because the degree of reduction appeared to be much more than twofold. The degree of colonization of the vascular system by $\mathrm{O}-685 \mathrm{G}$ was also noticeably reduced in the presence of CM14-2. Interestingly, we observed hyphae of CM14-2 in the vascular system of the plants coinoculated with $\mathrm{O}-685 \mathrm{G}$ in several areas that had been extensively colonized by $\mathrm{O}-685 \mathrm{G}$ (Supplementary Fig. 7), whereas vascular colonization was not observed in the roots inoculated with CM14-2 alone. This obser- vation suggested that $\mathrm{O}-685 \mathrm{G}$ facilitated the entry of CM14-2 to the vascular system. However, unlike hyphae of O-685G, which extensively proliferated in the vascular system, hyphae of CM14-2 remained near the site of entry.

To test whether CM14-2 alone could enter and ramify in the vascular system through wounds and cause disease symptoms, we inoculated physically wounded roots with CM14-2 and O$685 \mathrm{G}$ individually. Although CM14-2 managed to enter the vascular system through damaged root tips, the degree of its vascular colonization was markedly lower than that by $\mathrm{O}$ 685G. Furthermore, CM14-2 rarely reached the upper part of the root and mostly remained close to the original entry points.

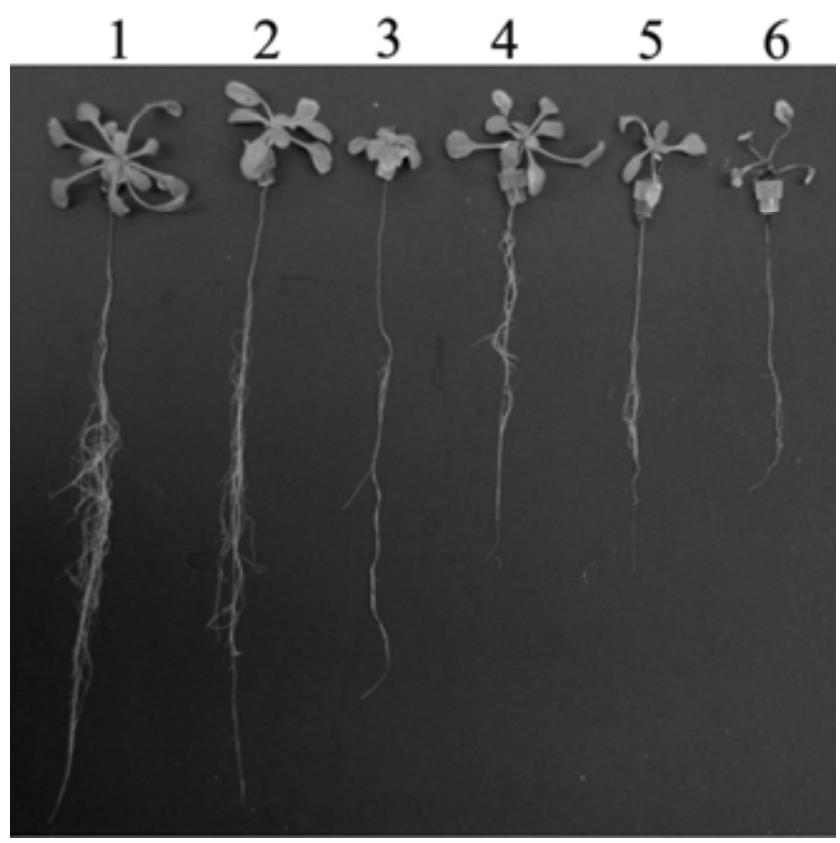

Fig. 7. In focpkA mutant and a strain nonpathogenic to Arabidopsis promoted plant growth. Two-week-old Cvi-0 plants grown in the hydroponic system were inoculated with 1, FOL4287 (a tomato isolate nonpathogenic to Arabidopsis); 2, CM14-2; 3, no conidia (control); 4, an equal mixture of spores from CM14-2 and $\mathrm{O}-685 \mathrm{G}$; 5 , an equal mixture of spores from FOL4287 and O-685G; and 6, O-685G. The final concentration of conidia was $2 \times 10^{6}$ conidia/ml. These plants were pictured at 27 days postinoculation.
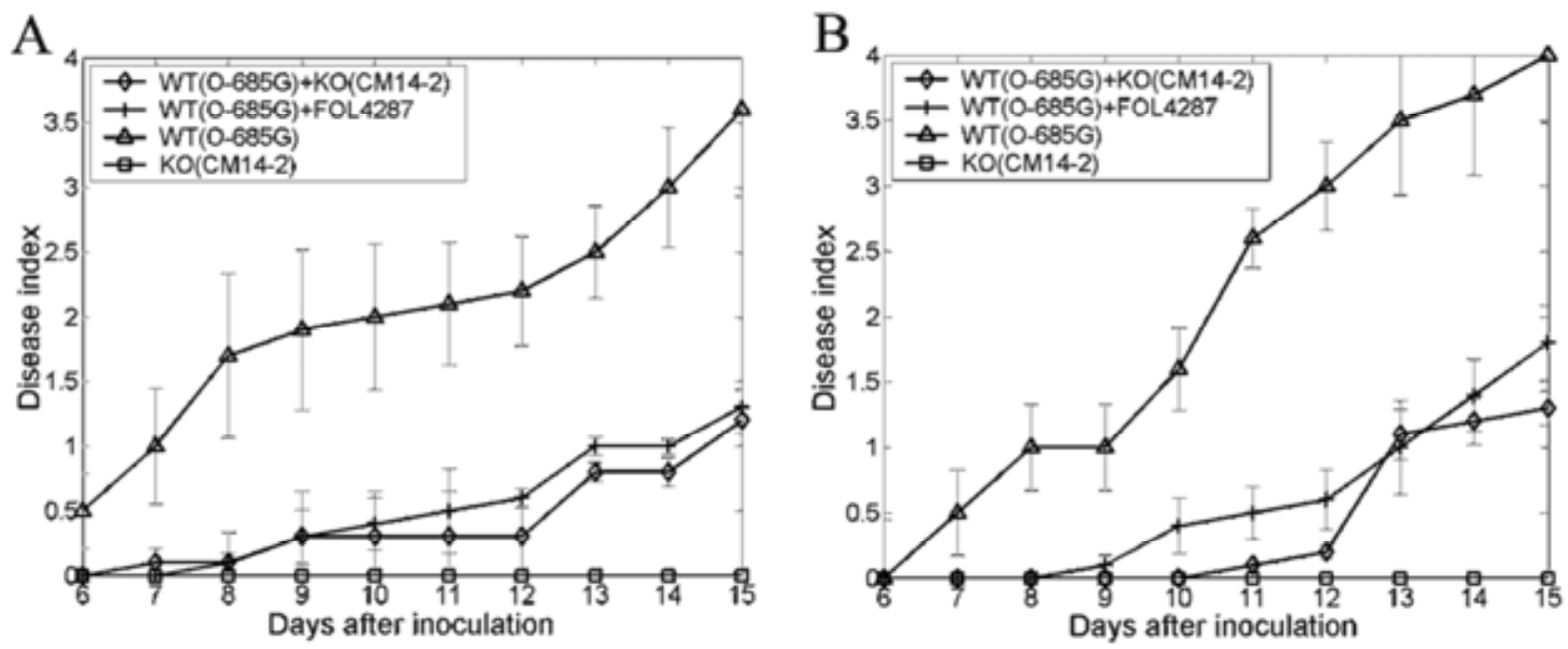

Fig. 6. Coinoculation of $\mathrm{O}-685 \mathrm{G}$ with nonpathogenic strains significantly reduced disease severity. Two-week old, hydroponically grown plants of ecotype Cvi-0 were inoculated with $\mathbf{A}, 1 \times 10^{6}$ conidia/ml and B, $2 \times 10^{6}$ conidia/ml. Spores of O-685G were mixed with equal numbers of CM14-2 or FOL4287 spores. Disease progression was monitored every day starting at 6 days postinoculation. Error bars indicate error of the mean derived from 12 plants for each strain (in each experiment) in two independent experiments. 
The plants infected with CM14-2 did not show noticeable symptoms at $14 \mathrm{dpi}$, whereas those infected with O-685G showed severe symptoms (Supplementary Fig. 8).

During the coinoculation experiments, we noticed that the plants inoculated with FOL4287 and CM14-2 grew faster than uninoculated control plants. The difference between them was not obvious at $14 \mathrm{dpi}$ (data not shown) but became pronounced at $27 \mathrm{dpi}$ (Fig. 7). Both the roots and foliar tissues of the plants inoculated with FOL4287 and CM14-2 grew bigger than those of the control plants. We noticed a similar growth promotion effect among the plants grown and inoculated in soil.

\section{DISCUSSION}

The limited understanding of the molecular and cellular mechanisms underpinning root diseases by soilborne fungal pathogens is due, in large part, to technical difficulties of studying disease progression in root tissues, because root-pathogen interactions are concealed within the soil and can be affected by many biotic and abiotic factors in the rhizosphere. We established an A. thaliana-F. oxysporum pathosystem and multiple platforms for plant growth and infection (Fig. 2) and analytical methods (Figs. 4 and 5) (Czymmek et al. 2007). These tools, in combination with the availability of genome sequences of $F$. oxysporum (Ma et al. 2010) and A. thaliana (The Arabidopsis Genome Initiative 2000) and the genetic tractability of both organisms, make this pathosystem an excellent "soilborne fungal disease" model for systematic analysis of pathogenicity factors and plant defense mechanisms. The focus of this study was on the roles of the F. oxysporum FoCPKA gene in cultural growth and infection of Arabidopsis roots.

\section{Imaging tools for studying fungal root pathogenesis.}

In a previous study (Czymmek et al. 2007), we employed fluorescent protein-labeled strains of $F$. oxysporum and a coverslip-bottomed chamber for plant growth and infection to enable microscopic monitoring of dynamic changes during $A$. thaliana $-F$. oxysporum interactions from both the host and pathogen sides. Because this approach does not require physical manipulation of roots for microscopic observation, we could avoid potential artifacts caused by wounds or sudden environmental and physical changes from manipulating roots and manage to observe the same plants at multiple time points, thus enabling time-lapse studies. With this system as well as a home-made hydroponic platform, root pathogenesis by the $F$. oxysporum WT and mutant strains labeled with two spectrally different fluorescent proteins were compared microscopically; this comparison revealed the nature of pathogenesis defects caused by the loss of FoCPKA (Fig. 3) and potential interactions between the WT and mutant strains in the same plants.

Electron microscopy reveals nanoscale structural features both on the surface and inside of cells and their interfaces but requires fixation of specimen. AFM circumvents the need for fixing cells and allows the imaging of nanoscale physical properties of cells and tissues in native states (Dupres et al. 2010). AFM is quite versatile and enables many biological applications, such as i) imaging the cell surface and its change over time (Dague et al. 2008), ii) characterizing cell surface physicochemical properties (Dupres et al. 2010; Stolz et al. 2004), iii) measuring interaction strengths between two different molecules (Panorchan et al. 2006), iv) probing structure and conformation changes of single proteins (Muller and Engel 2007), and v) investigating the properties of biological membranes (Mingeot-Leclercq et al. 2008). We demonstrated how disruption of FoCPKA affected spore surface topography and spore adhesion to the root surface (Figures 4 and 5); therefore, AFM can support studies on the gene function-surface property relationships underpinning plant-pathogen interactions.

\section{Loss of FoCPKA affected multiple traits important for root pathogenesis.}

Disruption of FoCPKA resulted in loss of virulence of $F$. oxysporum to A. thaliana. In all three platforms that we used to infect plants (Fig. 2), none of the plants infected with CM14-2 showed disease symptoms. Cytological analyses of the root colonization process by CM14-2 revealed multiple changes that contributed to its loss of virulence, including i) reduction in the number of spores attached to the root surface and in their binding affinity (Fig. 4), ii) inability to penetrate into the vascular system (Fig. 3), and iii) severely reduced ability to colonize the vascular tissue even when the mutant entered the vascular system through physical wounds or with assistance from WT strain O-685G. Analysis of the root infection process by this WT strain, conducted using time-lapse confocal microscopy (Czymmek et al. 2007), provided a few clues as to why CM14-2 failed to invade the vascular system and cause disease symptoms.

Penetration to the vascular system by O-685 occurred primarily through the meristematic zone of primary and lateral roots (Czymmek et al. 2007). Time-lapse microscopic observations of multiple vascular invasion events at both locations consistently showed that hyphal invasion to the vascular system immediately followed the collapse of the meristematic zone colonized by fungal hyphae. These observations suggested that the tissue collapse enabled hyphal entry to the vascular system. As fungal hyphae proliferated at the meristematic zone, root growth became arrested and, shortly thereafter, the colonized tissue collapsed, presumably because a large number of cells underwent death or lost turgor pressure, presumably due to yet-to-be-identified phytotoxins from the fungus (Czymmek et al. 2007). We hypothesize that, as the concentration of phytotoxins produced by the fungus reaches a critical point, roots cells stop dividing and, once the concentration passes the level root cells can tolerate, cells undergo death, leading to the observed tissue collapse. This probably is why the fungus had to reach a certain biomass before vascular invasion. Two lines of evidence suggested that phytotoxins might also be important for hyphal proliferation in the vascular system (Czymmek et al. 2007). Another line of evidence supporting the production of phytotoxins during the colonization of the vascular system is that we did not detect the fungus in the leaves exhibiting yellowing of the vascular tissue during early stages of infection (S. Park, unpublished data), suggesting the spread of phytotoxins into foliar tissues through the vascular system ahead of fungal colonization. Of course, it is formally possible that this foliar symptom was caused by simple nutrient deprivation due to blockage of vascular tissues. We hypothesize that loss of FoCPKA disrupted the production of phytotoxins, making the mutants incapable of invading the vascular system. This defect also probably hampered the ability of the mutant to grow inside the vascular system and cause disease symptoms even if it managed to enter the vascular system through physical wounds. However, all evidence supporting the involvement of phytotoxins was circumstantial, and we cannot discount alternative explanations (e.g., inability of the mutant to shift from saprophytic growth to infectious growth or defects in producing other types of virulence factors) for the failure of penetration to the vascular system and its markedly reduced ability to grow inside the vascular system.

Additional defects could also contribute to compromising virulence. The number of CM14-2 spores attached to the root surface was drastically lower than that of O-685G. This reduction in spore attachment certainly decreased the fungal biomass 
on the root surface. The degree of spore attachment to $A$. thaliana Cvi-0, an ecotype that is highly susceptible to $\mathrm{O}-685 \mathrm{G}$, was significantly higher than that observed in ecotype Greenville (Gre-0), which is highly resistant to O-685G (S. Park, unpublished data). These results suggest that efficient spore attachment is a key trait for successful pathogenesis. AFM data showed that the mutation reduced the adhesion strength of spores to the root surface (Fig. 4). Although the question of why and how the spore surface topography was affected by the mutation remains to be addressed, alteration of the spore surface (Fig. 5) may be responsible for the reduced spore attachment.

The foliar and appressoria-forming fungi Magnaporthe oryzae, Colletotrichum trifolii, and C. lagenarium also exhibited severe defects in host penetration or in planta proliferation when their CPKA was mutated. Their mutants formed appressoria but were unable to penetrate host tissues (Xu et al. 1997; Yamauchi et al. 2004; Yang and Dickman 1999). The $M$. oryzae and $C$. trifolii mutants were capable of causing disease symptoms when host tissues were wounded, suggesting that their ability of infectious growth was not affected by the mutation. However, the $C$. lagenarium mutant was defective in both processes. In contrast, B. cinerea (Schumacher et al. 2008) and Mycosphaerella graminicola (Mehrabi and Kema 2006), species that do not form appressoria, appeared normal in host penetration but their virulence was reduced. In $U$. maydis, the mutation resulted in complete loss of virulence (Dürrenberger et al. 1998). Considering the near WT-level virulence of the mutant of $F$. verticillioides in corn stalk rot assays, host penetration and in planta proliferation probably were not significantly affected by the mutation (Choi and $\mathrm{Xu}$ 2010). In $V$. dahliae, another root pathogen that causes vascular wilt diseases, the degree of virulence was attenuated in cpka mutants (Tzima et al. 2010). However, given the colonization of the vascular system by the mutant, host penetration was not blocked, suggesting that $V$. dahliae penetrates into the vascular system using a mechanism distinct from that of $F$. oxysporum.

\section{Loss of FoCPKA affected multiple growth-related phenotypes.}

The FoCPKA gene appears to control multiple growthrelated characteristics, including i) radial growth on solid media; ii) formation of microconidia; and iii) germ tube shape, septation, and hyphal branching (Fig. 1). Germinated conidia of O-685G became swelled, with their germ tubes looking bulbous, whereas conidia of CM14-2 did not swell and produced a slim and slightly curved germ tube. Branching of hyphae in CM14-2 was noticeably less frequent than that of $\mathrm{O}-685 \mathrm{G}$, and the distance between septa in CM14-2 was longer than that of O-685G (Fig. 1). Growth-related defects were also observed in cpka mutants in diverse fungal species (Banno et al. 2005; Choi and Xu 2010; Gold et al. 1994; Liebmann et al. 2004; Mitchell and Dean 1995; Schumacher et al. 2008; Shimizu and Keller 2001; Tzima et al. 2010; Xu and Hamer 1996; Yamauchi et al. 2004; Yang and Dickman 1999), suggesting the evolutionary conserved importance of the CPKA signaling pathway in controlling fungal growth and development.

Mutations in the $F$. oxysporum gene encoding heterotrimeric $\mathrm{G}$ protein $\beta$ subunit $(F G B 1)$, a gene that works upstream of FoCPKA, resulted in similar growth-related phenotypes, including altered colony morphology, highly elongated cells, less subapical branching, longer distance between septa, and reduced virulence (Jain et al. 2003, 2005). Similarly, inactivation of FGA1, an F. oxysporum gene encoding one of the $\mathrm{G} \alpha$ subunits, caused altered colony morphology and reduced conidiation and virulence (Jain et al. 2002). Phenotypes of the $f g b l$ and fgal mutants were partly restored by the application of exogenous cAMP (Delgado-Jarana et al. 2005). Interestingly, disruption of $F G A 2$, a gene encoding another $\mathrm{G} \alpha$ subunit, did not cause alteration in colony morphology and conidiation but led to complete loss of virulence (Jain et al. 2005).

\section{Nonpathogenic strains of $F$. oxysporum interfered with O-685G during infection, resulting in reduced disease symptoms.}

Plants coinoculated with O-685G and CM14-2 exhibited disease symptoms that are noticeably less severe than those inoculated with O-685G alone (Figs. 6 and 7). A strain nonpathogenic to A. thaliana (FOL4287; tomato pathogen) also protected plants from $\mathrm{O}-685 \mathrm{G}$ at a level similar to that by CM14-2. These results suggested that the presence of these strains interfered with O-685G's ability to infect Arabidopsis roots. The interference was notable at the level of spore attachment to the root surface. In the presence of CM14-2 or FOL4287, the number of O-685G spores attached to the root surface decreased greater than twofold. Considering that O$685 \mathrm{G}$ spores attached to the root surface much more efficiently than those of CM14-2, competition with spores of CM14-2 or FOL4287 for binding to the same sites did not appear to be the only cause of this reduction. In contrast to the reduction of spore binding in O-685G, the number of CM14-2 spores attached to the roots in the presence of O-685G appeared to be greater than that of the plants inoculated with CM14-2 alone, suggesting that the presence of $\mathrm{O}-685 \mathrm{G}$ spores helped the spores of CM14-2 attach to the root surface more efficiently. This opposite effect on spore attachment also supports the involvement of more than physical competition in suppressing disease development by $\mathrm{O}-685 \mathrm{G}$.

Both CM14-2 and FOL4287 failed to completely protect Arabidopsis roots from O-685G. However, considering that equal numbers of spores were used in our assays, the degree of protection will likely increase as the proportion of CM14-2 or FOL4287 spores increases. Effective control of Fusarium tomato wilt by nonpathogenic $F$. oxysporum Fo-B2 was observed when the inoculum densities of the Fo-B2 strain was at least 10fold greater than a pathogenic strain (Shishido et al. 2005). The observed growth promotion of plants inoculated with CM14-2 or FOL4287 (Fig. 7) suggested that nonpathogenic strains can potentially provide additional benefits. A similar growth promotion was observed in tomato plants inoculated with $V$. dahliae mutants in CPKA (Tzima et al. 2010). Successful field application of nonpathogenic strains of $F$. oxysporum as a biocontrol agent requires advances in multiple areas, including discovery and development of effective strains, better understanding of the mechanisms of action and ecology of biocontrol agents, and optimization of production, formulation, and delivery of the agent (Fravel et al. 2003). The pathosystem and associated tools presented here can potentially contribute to enhancing our understanding of biocontrol mechanisms. Targeted genetic manipulation of promising strains can also improve their biocontrol activity while minimizing risk. For example, naturally isolated biocontrol strains may still maintain virulence on certain hosts, posing the risk that biocontrol strains may become a pathogen of other plants near the area of application in the long run. However, due to a broad host range of the species, it would be difficult to evaluate their virulence potential on a diverse array of potential host plants. Disruption of a gene that is essential for pathogenicity but is dispensable for growth in the rhizosphere is a potential strategy for eliminating this risk. Similar to our observation, a nonpathogenic mutant of $F$. oxysporum, caused by the loss of class $\mathrm{V}$ chitin synthase, elicited defense responses in tomato plants and protected the inoculated plants from infection by a pathogenic strain of $F$. oxysporum (Pareja-Jaime et al. 2010). Addition of a gene that provides a competitive edge to biocontrol strains also deserves evaluation. 


\section{MATERIALS AND METHODS}

Fungal and bacterial isolates and culture conditions.

F. oxysporum isolates O-685 (Czymmek et al. 2007; OspinaGiraldo et al. 2003) and FOL4287 (Di Pietro et al. 2001) were obtained from the Fusarium Research Center at the Pennsylvania State University (University Park). Cultures stored at $-80^{\circ} \mathrm{C}$ were revitalized by culturing on $1 \%$ water agar supplemented with irradiated carnation leaf pieces. Microconidia were produced in carboxymethyl cellulose (CMC) broth (15 g of CMC, $1 \mathrm{~g}$ of yeast extract, $0.5 \mathrm{~g}$ of $\mathrm{MgSO}_{4}, 1 \mathrm{~g}$ of $\mathrm{NH}_{4} \mathrm{NO}_{3}$, and $1 \mathrm{~g}$ of $\mathrm{KH}_{2} \mathrm{PO}_{4}$ per liter) by shaking the culture $(100 \mathrm{rpm})$ at room temperature. After filtering through Miracloth (Calbiochem, La Jolla, CA, U.S.A.), spores were harvested by centrifugation and washed twice with sterile water. For fungal genomic DNA extraction, cultures were grown in PD broth. Agrobacterium tumefaciens EHA105, used for ATMT of $F$. oxysporum, was maintained and cultured as previously described (Mullins et al. 2001). Cloning and maintenance of the constructs used in this study were performed using Escherichia coli DH5 $\alpha$.

\section{Construction of vectors expressing fluorescent proteins and cloning of FoCPKA.}

The ZsGreen and AsRed genes under the control of the $F$. verticillioides elongation factor $1 \alpha$ gene promoter were amplified by polymerase chain reaction (PCR) using the primers Coral-F (5'-CGG TAC CTA TAG GGC GAA TTG GGT AC$\left.3^{\prime}\right)$ and EGFP-R (5'-TCA GAC AAG CTT ATC ATC ATG CAA CAT GCA TG-3'). These primers carry KpnI and HindIII sites, respectively, to facilitate subsequent cloning. Amplified 1.7-kb DNA fragments were cloned into pGEM-TEasy vector (Promega Corp., Madison, WI, U.S.A.) and sequenced to confirm their sequences. The sequence-confirmed clones were digested with KpnI and HindIII to release the insert. Binary vectors pBGt-Green and pBGt-Red, carrying ZsGreen and AsRed, respectively, were constructed by cloning these fragments between the KpnI and HindIII sites in the multiple cloning sites of $\mathrm{pBGt}$. Binary vector $\mathrm{pBGt}$ was constructed by replacing the 2.2-kb XhoI-BstXI fragment of pCAMBIA1300 with a $1.5-\mathrm{kb}$ SalI-BstXI fragment containing the npt gene (conferring geneticin resistance) under the control of the Cochliobolus heterostrophus GPD gene promoter.

The cloning of FoCPKA was started before the genome of $F$. oxysporum was sequenced. Taking advantage of the close evolutionary relationship between $F$. oxysporum and $F$. verticillioides, a cDNA clone containing an $F$. verticillioides gene encoding the catalytic subunit of CPKA was used as a heterologous probe to screen a genomic library of O-685 (OspinaGiraldo et al. 2003). SacI-digested DNA of several positive lambda clones was hybridized with the same probe to identify restriction fragments containing the gene, and positive fragments were cloned into pBlueScript II KS- (Stratagene, La Jolla, CA, U.S.A.) and sequenced. Sequence data were analyzed with the Lasergene software package (DNASTAR). To construct a mutant allele of FoCPKA for gene disruption, we replaced the internal 0.36-kb EcoRV-SacII fragment of the gene with a 1.4-kb EcoRV-SacII fragment carrying the hygromycin B resistance gene $\left(H y g^{\mathrm{r}}\right)$ derived from of pCB1004. The resulting mutant allele was released using PstI and BamHI and cloned between the PstI and BamHI sites of pGKO1 (Khang et al. 2005) to produce pGKO1-focpkA.

\section{Fungal transformation, gene disruption, and complementation.}

An ATMT protocol developed for F. oxysporum (Mullins et al. 2001) was used to transform O-685 with pBGt-Green and pBGt-Red. MM amended with geneticin at $100 \mu \mathrm{g} / \mathrm{ml}$ was used to select transformants. Transformants were screened using a fluorescent microscope to identify ones expressing strong fluorescence. The growth characteristics and pathogenicity of several transformants were compared with those of O-685 to determine that ATMT did not affect these characters. Two transformants, one expressing ZsGreen (named O-685G) and the other expressing AsRed (named O-685R), were employed for subsequent analyses. Binary vector pGKO1-focpkA was introduced into A. tumefaciens EHA105 to disrupt FoCPKA in O-685R, as previously described (Khang et al. 2005). Putative mutants and some ectopic transformants were purified by isolating monoconidia and confirmed by PCR and genomic Southern analyses.

To demonstrate that the mutant phenotypes in pathogenicity and growth were not caused by additional mutations that had occurred during gene disruption, an focpkA mutant, CM14-2, was cotransformed with a 3.9-kb SacI fragment carrying the FoCPKA gene and its flanking sequences and a plasmid (pSK2959) that carries a gene (NAT) conferring resistance to nourseothricin under the control of the Aspergillus nidulans trpC promoter and the $N$. crassa $\beta$-tubulin terminator. This plasmid was linearized by HindIII digestion before transformation. Protoplasts of CM14-2 were prepared using a protocol developed for $F$. graminearum (Lee et al. 2002). After inoculating 10-ml culture of CM14-2 in CMC broth into $50 \mathrm{ml}$ of YPG $(0.3 \%$ yeast extract, $1 \%$ peptone, and $2 \%$ glucose) broth, the culture was grown for $13 \mathrm{~h}$ with shaking (100 rpm). Mycelia were harvested by filtration through sterilized Miracloth (Calbiochem), washed twice with $1 \mathrm{M} \mathrm{NH}_{4} \mathrm{Cl}(\mathrm{pH} 5.8)$, and then resuspended in $35 \mathrm{ml}$ of $1 \mathrm{M} \mathrm{NH}_{4} \mathrm{Cl}(\mathrm{pH} 5.8)$ amended with $1.5 \%$ Drisealse (Sigma-Aldrich, St Louis). After $3 \mathrm{~h}$ of incubation at $30^{\circ} \mathrm{C}$ with gentle shaking (approximately 50 rpm), protoplasts were harvested. For cotransformation, $1 \times$ $10^{7}$ protoplasts were combined with a mixture of two DNA fragments (approximately $5 \mu \mathrm{g}$ of each) in 60\% PEG3350 (Sigma-Aldrich). After incubation at room temperature for 30 min, protoplasts were mixed gently with $40 \mathrm{ml}$ of regeneration medium $(0.1 \%$ yeast extract, $0.1 \%$ caseinhydrolysate, $1 \mathrm{M}$ sucrose, and $1 \%$ agar at $42^{\circ} \mathrm{C}$ ) and poured into two petri plates. After $13 \mathrm{~h}$, the plates were overlaid with $10 \mathrm{ml}$ of selective CM containing nourseothricin $(60 \mu \mathrm{g} / \mathrm{ml})$. Nourseothricinresistant transformants were grown on CM amended with hygromycin B to identify hygromycin B-sensitive transformants, caused by the replacement of the focpkA mutant with the WT gene. Red fluorescence in the complemented strains was confirmed using a fluorescence microscope. MM amended with both geneticin at $100 \mu \mathrm{g} / \mathrm{ml}$ and nourseothricin at $30 \mu \mathrm{g} / \mathrm{ml}$ was used to isolate single spores from each transformants. Three complemented mutants were analyzed by PCR to confirm the restoration of the FoCPKA gene using the following primes: Com-CPKA F (5'-TCA CGA TCA TCA GAA CCT-3') and Com-CPKA R (5'-TCC AAA GCT AAA GTG ACC-3').

\section{Characterization of growth.}

To analyze growth characteristics, a mycelium plug $(2 \mathrm{~mm}$ in diameter) taken from the margin of fungal colonies on PD agar was placed at the center of three media, including CM, MM (Ospina-Giraldo et al. 2003), and PD. After incubating the plates at $25^{\circ} \mathrm{C}$ under the light for 6 days, the diameter of cultures was measured. Measurements were collected from three replicates in two independent experiments, and we applied Student's $t$ test for the resulting data.

For analysis of spore germination and hyphal growth and morphology, $20 \mu \mathrm{l}$ of $5 \times 10^{4}$ conidia $/ \mathrm{ml}$ inoculated in each of the three media was sandwiched between two cover slips, mounted with paraffin, and incubated at $25^{\circ} \mathrm{C}$ under light. Germination, sporulation, and hyphal morphology were ob- 
served at multiple time points $(3,6,15,24$, and $38 \mathrm{~h})$. The septated hyphae were observed $24 \mathrm{~h}$ after staining with FM4$64 X$ (final concentration of $10 \mu \mathrm{g} / \mathrm{ml}$ ). FM4-64X data were acquired using a Zeiss LSM510 NLO Confocal microscope using a $\times 40 \mathrm{C}$-Apochromat (1.2 NA) water immersion objective lens (543-nm laser excitation and 560-nm long-pass emission filter).

\section{Evaluation of virulence.}

Seedlings of Arabidopsis thaliana ecotype Cape Verde Islands (Cvi-0), which is highly susceptible to O-685 (Ospina-Giraldo et al. 2003), were used to determine how disruption of FoCPKA affects pathogenicity and root colonization. Plants were grown in soil for comparing virulence between WT strains and the mutant, while microscopic observations of root infection processes were conducted using plants grown in the coverslip-bottomed chamber system (Czymmek et al. 2007) and a hydroponic system. Arabidopsis seed, purchased from Lehel Seed Co. (Round Rook, TX, U.S.A.), were sterilized by washing them with a solution of bleach and $\mathrm{dH}_{2} \mathrm{O}$ (3:1) for 20 min and were sown in 24-well microtiter plates (Cellstar, San Diego, CA, U.S.A.) filled with a mixture of sand/vermiculite/Metro-Mix200 (1:2:1) prewetted with sterile water. After incubating the plates at $4^{\circ} \mathrm{C}$ for 2 or 3 days, they were transferred to a growth chamber under a 16-h photoperiod with $8 \mathrm{~h}$ of darkness at $22^{\circ} \mathrm{C}$ and approximately $60 \%$ relative humidity. After germination, seedlings were thinned to one seedling per well. Inoculation of Arabidopsis seedlings was conducted by injecting $0.5 \mathrm{ml}$ of a $10^{6}$ conidia $/ \mathrm{ml}$ suspension into the soil at the base of the stem using a 1-ml micropipette tip. Control plants were inoculated with sterile water. The inoculated seedlings were not watered for $24 \mathrm{~h}$ to prevent the inoculum from being washed away from the root zone; however, following this period, plants were watered every day with sterile water and were fertilized with a $1 \times$ strength AN solution (Czymmek et al. 2007) twice a week. Disease symptoms were recorded using a numeric disease severity scale, where $0=$ healthy plant; 1 = first and second leaves just started expressing vein yellowing; 2 = first through fourth leaves became yellow, and fifth and sixth leaves started expressing vein yellowing; 3 = first through fourth leaves are dead and dried, and most leaves developed vein or leaf yellowing; and $4=$ whole plant is dead. Infection assays were repeated at least twice with a minimum of four seedlings per treatment.

\section{Microscopic observations of root colonization \\ by $\boldsymbol{F}$. oxysporum using \\ the coverslip-bottomed chamber system.}

For growing ecotype Cvi-0 seedlings in a single-welled LabTek chambered coverglass system (Nalgene Nunc International, Naperville, IL, U.S.A.), sterilized seed were individually sown on top of $0.7 \%$ agar (amended with $0.5 \times$ strength AN medium without sucrose). Imaging condition for confocal microscopy, plant growth conditions, time of reorientation chamber, and fungal inoculation point were described in a previous report (Czymmek et al. 2007). All confocal images of roots colonized by the fungus were obtained using a Carl Zeiss LSM510 NLO laser-scanning microscope using either a $\times 40$ oil PlanNeoFluor (1.3 NA) or $\times 40$ C-Apochromat (1.2 NA) water immersion objective lens. The following settings were used: 488$\mathrm{nm}$ laser line (ZsGreen) of a $15-\mathrm{mW}$ argon laser with a 500- to 530-band-pass emission filter, with the 543-nm helium/neon laser line for autofluorescence (plant cell walls). Alternatively, 543-nm excitation with a 560-nm long-pass emission filter (AsRed) and 488-nm laser excitation with 500- to 530-bandpass emission filter autofluorescence (plant cell walls) were used. Conditions of laser powers and image captures were described previously (Czymmek et al. 2007).

\section{Root colonization by $\boldsymbol{F}$. oxysporum in plants grown hydroponically.}

To grow Cvi-0 seedlings in a hydroponic system, sterilized seed were individually sown on the top of $0.7 \%$ agar (amended with $0.5 \times$ AN medium without sucrose)-filled 10- $\mu$ l micropipette tips (cut at approximately two-fifths from the top, where the tip starts narrowing). The tips were cut using a blade and sterilized before filling them with the agar medium. The tips, which were placed in a plastic micropipette tip holder, were suspended in a plastic container filled with $1 \times$ strength AN medium without sucrose (Fig. 2). Seedlings were grown in a growth chamber $\left(16 \mathrm{~h}\right.$ of light and $8 \mathrm{~h}$ of darkness, $\left.22^{\circ} \mathrm{C}\right)$. For infection, 2-week-old seedlings were transferred to a different container filled with the same nutrient solution amended with $1 \times 10^{6}$ conidia/ml.

Root attachment by spores, hyphal growth on the root surface, and root penetration were observed using an inverted microscope every day, starting from 1 to 15 dpi. Root colonization by the fungus was imaged using a Zeiss Axiovert 200 (Oberkochen, Germany) fluorescence microscope using $\times 20$ Plan-Apochromat $(0.75 \mathrm{NA})$ and $\times 40$ oil Plan-NeoFluor $(1.3$ NA) lenses. Conditions for confocal imaging were described above.

To compare the degree of root attachment by spores of O685G and CM14-2, the roots of 2-week-old seedlings were immersed in a conidial suspension $\left(1 \times 10^{6}\right.$ conidia $\left./ \mathrm{ml}\right)$ in $1 \times$ strength AN medium for $72 \mathrm{~h}$ and then transferred to Erlenmeyer flasks containing sterilized water for washing. After shaking vigorously at $25^{\circ} \mathrm{C}$ for different time points $(3,10$, and $24 \mathrm{~h}$ ), the degree of spore attachment to the root surface was assessed using a Zeiss Axiovert 200 microscope.

Inoculation of hydroponically grown plants with mixes of spores from O-685G and CM14-2 at two different concentrations, $1 \times 10^{6}$ and $2 \times 10^{6}$ conidia/ml, were conducted as described above. For controls, spores of O-685G and CM14-2 at two different concentrations $\left(1 \times 10^{6}\right.$ and $2 \times 10^{6}$ conidia/ml $)$ were used. To determine whether CM14-2 could enter the vascular system via physical wounds, after cutting approximately $1 \mathrm{~cm}$ above the primary root tip of 2-week-old, hydroponically grown seedlings using a sterilized scissor, the wounded roots were immediately immersed in a spore suspension $\left(1 \times 10^{6}\right.$ conidia/ml). Fungal colonization was monitored using a Zeiss Axiovert 200 microscope.

To compare the degree of the root and vegetative plant growth in the presence of O-685G, CM14-2, FOL4287, and mixtures of O-685G with FOL4287 and CM14-2, 2-week-old seedlings grown hydroponically were immersed in $1 \times$ strength AN medium amended with spores $\left(1 \times 10^{6}\right.$ conidia $\left./ \mathrm{ml}\right)$. The inoculated plants were taken from the hydroponic system carefully and pictured at two different time points (14 and $27 \mathrm{dpi}$ ).

\section{AFM.}

To evaluate affinities of root attachment by spores of $F$. oxysporum, unbinding forces of spores from the root surface of 2 week-old seedlings grown in the hydroponic system were measured using AFM. The AFM tips were coated with fungal spores using the amine coupling method (Stevens et al. 2002). First, tips were cleaned by a piranha solution (30\% hydrogen peroxide and $70 \%$ sulfuric acid), then coated with a self-assembled monolayer terminated with silane. Second, tips were silanized in a 4\% solution of 3-aminopropyldimethylethoxysilane (Gelest Inc., Morrisville, PA, U.S.A.) in $95 \%$ ethanol in water for $1 \mathrm{~h}$ at room temperature. Third, after removing weakly bound silane by washing tips in ethanol and drying for $5 \mathrm{~min}$ at $100^{\circ} \mathrm{C}$, tips were then incubated for $1 \mathrm{~h}$ in a final concentration of $0.25 \%$ glutaraldehyde (EMS, Fort Washington, PA, U.S.A.) and F. oxysporum $\left(1 \times 10^{7}\right.$ conidia/ml $)$. Finally, 
tips were washed with sterilized pure water and stored in double-distilled water at $4^{\circ} \mathrm{C}$ until use. To confirm the presence of the spores on the AFM tips, the tips were imaged using confocal microscopy. Seedlings were positioned on a glass slide and the root tip and $2 \mathrm{~cm}$ from the root tip were targeted for measurements of unbinding forces. All measurements were performed with approximately 1,000 force curves on each of the two regions. Of these, approximately 250 were performed at different areas within each region, to make sure that the sampling was representative of the whole area investigated. Force curves were reviewed and curves showing single force interactions were further analyzed. All experiments were performed with two replicates and repeated three times using different tips. For surface imaging, microconidia were first washed four times in distilled water and then $100 \mu \mathrm{l}$ of cell suspension was deposited onto a poly-lysine-coated coverslip. The cells were allowed to incubate on the coverslips for $1 \mathrm{~h}$ at room temperature and then washed with distilled water. Samples were then allowed to dry at room temperature for $1 \mathrm{~h}$. The cells were then imaged using tapping mode with silicon tips (RTESP, Bruker Instruments, Santa Barbara, CA, U.S.A.) in air on the Bioscope II AFM (Bruker Instruments).

\section{LITERATURE CITED}

Adachi, K., and Hamer, J. E. 1998. Divergent cAMP signaling pathways regulate growth and pathogenesis in the rice blast fungus Magnaporthe grisea. Plant Cell 10:1361-1374.

Banno, S., Ochiai, N., Noguchi, R., Kimura, M., Yamaguchi, I., Kanzaki, S.-I., Murayama, T., and Fujimura, M. 2005. A catalytic subunit of cyclic AMP-dependent protein kinase, $P K A C$-1, regulates asexual differentiation in Neurospora crassa. GenesGenet. Syst. 80:25-34.

Baroni, M. D., Monti, P., and Alberghina, L. 1994. Repression of growthregulated G1 cyclin expression by cyclic AMP in budding yeast. Nature 371:339-342.

Bockmühl, D., Krishnamurthy, S., Gerads, M., Sonneborn, A., and Ernst, J. 2001. Distinct and redundant roles of the two protein kinase A isoforms Tpklp and Tpk2p in morphogenesis and growth of Candida albicans. Mol. Microbiol. 42:1243-1257.

Bölker, M. 1998. Sex and crime: Heterotrimeric G proteins in fungal mating and pathogenesis. Fungal Genet. Biol. 25:143-156.

Borges-Walmsley, M. I., and Walmsley, A. R. 2000. cAMP signaling in pathogenic fungi: Control of dimorphic switching and pathogenicity. Trends Microbiol. 8:133-141.

Brakhagea, A. A., and Liebmanna, B. 2005. Aspergillus fumigatus conidial pigment and cAMP signal transduction: Significance for virulence. Med. Mycol. 43:75-82.

Bruno, K. S., Aramayo, R., Minke, P. F., Metzenberg, R. L., and Plamann, M. 1996. Loss of growth polarity and mislocalization of septa in a $\mathrm{Neu}$ rospora mutant altered in the regulatory subunit of cAMP-dependent protein kinase. EMBO (Eur. Mol. Biol. Soc.) J. 15:5772-5782.

Chen, R. E., and Thorner, J. 2007. Function and regulation in MAPK signaling pathways: Lessons learned from the yeast Saccharomyces cerevisiae. Biochim. Biophys. Acta (BBA) Mol. Cell Res. 1773:1311-1340.

Choi, W.-B., Kang, S.-H., Lee, Y.-W., and Lee, Y.-H. 1998. Cyclic AMP restores appressorium formation inhibited by polyamines in Magnaporthe grisea. Phytopathology 88:58-62.

Choi, Y.-E., and Xu, J.-R. 2010. The cAMP signaling pathway in Fusarium verticillioides is important for conidiation, plant infection, and stress responses but not fumonisin production. Mol. Plant-Microbe Interact. 23:522-533.

Cloutier, M., Castilla, R., Bolduc, N., Zelada, A., Martineau, P., Bouillon, M., Magee, B. B., Passeron, S., Giasson, L., and Cantore, M. L. 2003. The two isoforms of the cAMP-dependent protein kinase catalytic subunit are involved in the control of dimorphism in the human fungal pathogen Candida albicans. Fungal Genet. Biol. 38:133-141.

Czymmek, K. J., Fogg, M., Powell, D. H., Sweigard, J., Park, S.-Y., and Kang, S. 2007. In vivo time-lapse documentation using confocal and multi-photon microscopy reveals the mechanisms of invasion into the Arabidopsis root vascular system by Fusarium oxysporum. Fungal Genet. Biol. 44:1011-1023.

Dague, E., Alsteens, D., Latgé, J.-P., and Dufrêne, Y. F. 2008. High-resolution cell surface dynamics of germinating Aspergillus fumigatus conidia. Biophys. J. 94:656-660.

Delgado-Jarana, J., Martínez-Rocha, A. L., Roldán-Rodriguez, R. G.,
Roncero, M. I., and Pietro, A. D. 2005. Fusarium oxysporum G-protein $\beta$ subunit Fgbl regulates hyphal growth, development, and virulence through multiple signalling pathways. Fungal Genet. Biol. 42:61-72.

Dickman, M. B., Ha, Y. S., Yang, Z., Adams, B., and Huang, C. 2007. A protein kinase from Colletotrichum trifolii is induced by plant cutin and is required for appressorium formation. Mol. Plant-Microbe Interact. 16:411-421.

Di Pietro, A., García-Maceira, F. I., Méglecz, E., and Roncero, M. I. G. 2001. A MAP kinase of the vascular wilt fungus Fusarium oxysporum is essential for root penetration and pathogenesis. Mol. Microbiol. 39:1140-1152.

Doehlemann, G., Berndt, P., and Hahn, M. 2006. Different signalling pathways involving a G $\alpha$ protein, cAMP and a MAP kinase control germination of Botrytis cinerea conidia. Mol. Microbiol. 59:821-835.

D'Souza, C. A., and Heitman, J. 2001. Conserved cAMP signaling cascades regulate fungal development and virulence. FEMS (Fed. Eur. Microbiol. Soc.) Microbiol. Rev. 25:349-364.

D'Souza, C. A., Alspaugh, J. A., Yue, C., Harashima, T., Cox, G. M., Perfect, J. R., and Heitman, J. 2001. Cyclic AMP-dependent protein kinase controls virulence of the fungal pathogen Cryptococcus neoformans. Mol. Cell. Biol. 21:3179-3191.

Dupres, V., Alsteens, D., Andre, G., and DufrÍne, Y. F. 2010. Microbial nanoscopy: A closer look at microbial cell surfaces. Trends Microbiol. 18:397-405.

Dürrenberger, F., Wong, K., and Kronstad, J. W. 1998. Identification of a cAMP-dependent protein kinase catalytic subunit required for virulence and morphogenesis in Ustilago maydis. Proc. Natl. Acad. Sci. U.S.A. 95:5684-5689.

Fillinger, S., Chaveroche, M.-K., Shimizu, K., Keller, N., and d'Enfert, C. 2002. cAMP and ras signalling independently control spore germination in the filamentous fungus Aspergillus nidulans. Mol. Microbiol. 44:1001-1016.

Fravel, D., Olivain, C., and Alabouvette, C. 2003. Fusarium oxysporum and its biocontrol. New Phytol. 157:493-502.

Freitas, F. Z., de Paula, R. M. D., Barbosa, L. C., Terenzi, H. F., and Bertolini, M. C. 2010. cAMP signaling pathway controls glycogen metabolism in Neurospora crassa by regulating the glycogen synthase gene expression and phosphorylation. Fungal Genet. Biol. 47:43-52.

Fuchs, J.-G., Moënne-Loccoz, Y., and Défago, G. 1997. Nonpathogenic Fusarium oxysporum strain Fo47 induces resistance to Fusarium Wilt in tomato. Plant Dis. 81:492-496.

Gerits, N., Kostenko, S., Shiryaev, A., Johannessen, M., and Moens, U. 2008. Relations between the mitogen-activated protein kinase and the cAMP-dependent protein kinase pathways: Comradeship and hostility. Cell. Signal. 20:1592-1607.

Gold, S. E., Duncan, G. A., Barrett, K. J., and Kronstad, J. W. 1994. cAMP regulates morphogenesis in the fungus Ustilago maydis. Genes Dev. 8:2805-2816

Gold, S. E., Brogdon, S. M., Mayorga, M. E., and Kronstad, J. W. 1997. The Ustilago maydis regulatory subunit of a cAMP-dependent protein kinase is required for gall formation in maize. Plant Cell 9:1585-1594.

Grosse, C., Heinekamp, T., Kniemeyer, O., Gehrke, A., and Brakhage, A. A. 2008. Protein kinase A regulates growth, sporulation, and pigment formation in Aspergillus fumigatus. Appl. Environ. Microbiol. 74:49234933

Hatanaka, M., and Shimoda, C. 2001. The cyclic AMP/PKA signal pathway is required for initiation of spore germination in Schizosaccharomyces pombe. Yeast 18:207-217.

Hicks, J. K., D'Souza, C. A., Cox, G. M., and Heitman, J. 2004. Cyclic AMP-dependent protein kinase catalytic subunits have divergent roles in virulence factor production in two varieties of the fungal pathogen Cryptococcus neoformans. Eukaryot. Cell 3:14-26.

Ivey, F. D., Yang, Q., and Borkovich, K. A. 1999. Positive regulation of adenylyl cyclase activity by a $\mathrm{G} \alpha_{\mathrm{i}}$ homolog in Neurospora crassa. Fungal Genet. Biol. 26:48-61.

Jain, S., Akiyama, K., Mae, K., Ohguchi, T., and Takata, R. 2002. Targeted disruption of a $\mathrm{G}$ protein $\alpha$ subunit gene results in reduced pathogenicity in Fusarium oxysporum. Curr. Genet. 41:407-413.

Jain, S., Akiyama, K., Kan, T., Ohguchi, T., and Takata, R. 2003. The G protein $\beta$ subunit $F G B 1$ regulates development and pathogenicity in Fusarium oxysporum. Curr. Genet. 43:79-86.

Johnson, L.N., Noble, M.E.M., and Owen, D.J. 1996. Active and inactive protein kinases: Structural basis for regulation. Cell 85:149-158.

Jain, S., Akiyama, K., Takata, R., and Ohguchi, T. 2005. Signaling via the $\mathrm{G}$ protein $\alpha$ subunit FGA2 is necessary for pathogenesis in Fusarium oxysporum. FEMS (Fed. Eur. Microbiol. Soc.) Microbiol. Lett. 243:165-172.

Kahmann, R., Basse, C., and Feldbrügge, M. 1999. Fungal-plant signalling in the Ustilago maydis-maize pathosystem. Curr. Opin. Microbiol. 2:647-650. 
Kang, S. H., Khang, C. H., and Lee, Y.-H. 1999. Regulation of cAMP-dependent protein kinase during appressorium formation in Magnaporthe grisea. FEMS (Fed. Eur. Microbiol. Soc.) Microbiol. Lett. 170:419423.

Kays, A. M., Rowley, P. S., Baasiri, R. A., and Borkovich, K. A. 2000 Regulation of conidiation and adenylyl cyclase levels by the $\mathrm{G} \alpha$ protein GNA-3 in Neurospora crassa. Mol. Cell. Biol. 20:7693-7705.

Khang, C. H., Park, S.-Y., Lee, Y.-H., and Kang, S. 2005. A dual selection based, targeted gene replacement tool for Magnaporthe grisea and Fusarium oxysporum. Fungal Genet. Biol. 42:483-492.

Kore-Eda, S., Murayama, T., and Uno, I. 1991. Isolation and characterization of the adenylate cyclase structural gene of Neurospora crassa. Jpn. J. Genet. 66:317-334.

Kraakman, L., Lemaire, K., Ma, P., Teunissen, A. W., Donaton, M. C., Van Dijck, P., Winderickx, J., De Winde, J. H., and Thevelein, J. M. 1999. A Saccharomyces cerevisiae G-protein coupled receptor, Gprl, is specifically required for glucose activation of the cAMP pathway during the transition to growth on glucose. Mol. Microbiol. 32:1002-1012.

Kronstad, J., De Maria, A., Funnell, D., Laidlaw, R. D., Lee, N., de Sá, M. M., and Ramesh, M. 1998. Signaling via cAMP in fungi: Interconnections with mitogen-activated protein kinase pathways. Arch. Microbiol. 170:395-404

Krüger, J., Loubradou, G., Regenfelder, E., Hartmann, A., and Kahmann, R. 1998. Crosstalk between cAMP and pheromone signalling pathways in Ustilago maydis. Mol. Gen. Genet. 260:193-198.

Lafon, A., Han, K.-H., Seo, J.-A., Yu, J.-H., and d'Enfert, C. 2006. G-protein and cAMP-mediated signaling in aspergilli: A genomic perspective. Fungal Genet. Biol. 43:490-502.

Lee, N., D’Souza, C. A., and Kronstad, J. W. 2003. Of smuts, blasts, mildew, and blights: cAMP signaling in phytopathogenic fungi. Annu. Rev. Phytopathol. 41:399-427.

Lee, T., Han, Y.-K., Kim, K.-H., Yun, S.-H., and Lee, Y.-W. 2002. Tri13 and Tri7 determine deoxynivalenol- and nivalenol-producing chemotypes of Gibberella zeae. Appl. Environ. Microbiol. 68:2148-2154.

Lee, Y. H., and Dean, R. A. 1993. cAMP regulates infection structure formation in the plant pathogenic fungus Magnaporthe grisea. Plant Cell 5:693-700.

Lengeler, K. B., Davidson, R. C., D'Souza, C., Harashima, T., Shen, W.C., Wang, P., Pan, X., Waugh, M., and Heitman, J. 2000. Signal transduction cascades regulating fungal development and virulence. Microbiol. Mol. Biol. Rev. 64:746-785.

Li, L., Wright, S. J., Krystofova, S., Park, G., and Borkovich, K. A. 2007. Heterotrimeric $G$ protein signaling in filamentous fungi. Annu. Rev. Microbiol. 61:423-452.

Liebmann, B., Gattung, S., Jahn, B., and Brakhage, A. A. 2003. cAMP signaling in Aspergillus fumigatus is involved in the regulation of the virulence gene $p k s P$ and in defense against killing by macrophages. Mol. Genet. Genomics 269:420-435.

Liebmann, B., Muller, M., Braun, A., and Brakhage, A. A. 2004. The cyclic AMP-dependent protein kinase A network regulates development and virulence in Aspergillus fumigatus. Infect. Immun. 72:5193-5203.

Ma, L.-J., van der Does, H. C., Borkovich, K. A., Coleman, J. J., Daboussi, M.-J., Di Pietro, A., Dufresne, M., Freitag, M., Grabherr, M., Henrissat, B., Houterman, P. M., Kang, S., Shim, W.-B., Woloshuk, C., Xie, X., Xu, J.-R., Antonxiw, J., Baker, S. E., Bluhm, B. H., Breakspear, A., Brown, D. W., Butchko, R. A. E., Chapman, S., Coulson, R., Coutinho, P. M., Danchin, E. J. G., Diener, A., Gale, L. R., Gardiner, D. M., Goff, S., Hammond-Kosack, K. E., Hilburn, K., Houterman, P. M., Hua-Van, A., Jonkers, W., Kazan, K., Kodira, C. D., Koehrsen, M., Kumar, L., Lee, Y.-H., Li, L., Manners, J. M., Miranda-Saavedra, D., Mukherjee, M., Park, G., Park, J., Park, S.-Y., Proctor, R. H., Regev, A., Ruiz-Roldan, M. C., Sain, D., Sakthikumar, S., Sykes, S., Schwartz, D. C., Turgeon, B. G., Wapinski, I., Yoder, O., Young, S., Zeng, Q., Zhou, S., Galagan, J., Cuomo, C. A., Kistler, H. C., and Rep, M. 2010. Comparative genomics reveals mobile pathogenicity chromosomes in Fusarium oxysporum. Nature 464:367-373

Maeda, T., Watanabe, Y., Kunitomo, H., and Yamamoto, M. 1994. Cloning of the pkal gene encoding the catalytic subunit of the cAMP-dependent protein kinase in Schizosaccharomyces pombe. J. Biol. Chem. 269:9632-9637.

Maidan, M. M., De Rop, L., Serneels, J., Exler, S., Rupp, S., Tournu, H., Thevelein, J. M., and Van Dijck, P. 2005. The G protein-coupled receptor $G p r l$ and the $\mathrm{G} \alpha$ protein $G p a 2$ act through the cAMP-protein kinase A pathway to induce morphogenesis in Candida albicans. Mol. Biol. Cell 16:1971-1986.

Martínez-Espinoza, A. D., Ruiz-Herrera, J., León-Ramírez, C. G., and Gold, S. E. 2004. MAP kinase and cAMP signaling pathways modulate the $\mathrm{pH}$-induced yeast-to-mycelium dimorphic transition in the corn smut fungus Ustilago maydis. Curr. Microbiol. 49:274-281.

Mehrabi, R., and Kema, G. H. J. 2006. Protein kinase A subunits of the ascomycete pathogen Mycosphaerella graminicola regulate asexual fructification, filamentation, melanization, and osmosensing. Mol. Plant Pathol. 7:565-577.

Mehrabi, R., M'Barek, S. B., van der Lee, T. A. J., Waalwijk, C., de Wit, P. J. G. M., and Kema, G. H. J. 2009. G $\alpha$ and G $\beta$ proteins regulate the cyclic AMP pathway that is required for development and pathogenicity of the phytopathogen Mycosphaerella graminicola. Eukaryot. Cell 8:1001-1013.

Mey, G., Held, K., Scheffer, J., Tenberge, K. B., and Tudzynski, P. 2002. $C P M K 2$, an SLT2-homologous mitogen-activated protein (MAP) kinase, is essential for pathogenesis of Claviceps purpurea on rye: Evidence for a second conserved pathogenesis-related MAP kinase cascade in phytopathogenic fungi. Mol. Microbiol. 46:305-318.

Mingeot-Leclercq, M.-P., Deleu, M., Brasseur, R., and Dufrene, Y. F. 2008. Atomic force microscopy of supported lipid bilayers. Nat. Protocols 3:1654-1659.

Mitchell, T. K., and Dean, R. A. 1995. The cAMP-dependent protein kinase catalytic subunit is required for appressorium formation and pathogenesis by the rice blast pathogen Magnaporthe grisea. Plant Cell 7:1869-1878.

Muller, D. J., and Engel, A. 2007. Atomic force microscopy and spectroscopy of native membrane proteins. Nat. Protocols 2:2191-2197.

Müller, P., Leibbrandt, A., Teunissen, H., Cubasch, S., Aichinger, C., and Kahmann, R. 2004. The G $\beta$-subunit-encoding gene bpp1 controls cyclic-AMP signaling in Ustilago maydis. Eukaryot. Cell 3:806-814.

Mullins, E. D., Chen, X., Romaine, P., Raina, R., Geiser, D. M., and Kang, S. 2001. Agrobacterium-mediated transformation of Fusarium oxysporum: An efficient tool for insertional mutagenesis and gene transfer. Phytopathology 91:173-180.

Nazarko, V. Y., Thevelein, J. M., and Sibirny, A. A. 2008. G-protein-coupled receptor $G p r l$ and G-protein Gpa2 of cAMP-dependent signaling pathway are involved in glucose-induced pexophagy in the yeast Saccharomyces cerevisiae. Cell Biol. Int. 32:502-504.

O'Donnell, K., Gueidan, C., Sink, S., Johnston, P. R., Crous, P. W., Glenn, A., Riley, R., Zitomer, N. C., Colyer, P., Waalwijk, C., Lee, T., Moretti, A., Kang, S., Kim, H.-S., Geiser, D. M., Juba, J. H., Baayen, R. P., Cromey, M. G., Bithell, S., Sutton, D. A., Skovgaard, K., Ploetz, R., Corby Kistler, H., Elliott, M., Davis, M., and Sarver, B. A. J. 2009. A two-locus DNA sequence database for typing plant and human pathogens within the Fusarium oxysporum species complex. Fungal Genet. Biol. 46:936-948.

Olivain, C., and Alabouvette, C. 1997. Colonization of tomato root by a non-pathogenic strain of Fusarium oxysporum. New Phytol. 137:481494.

Olivain, C., and Alabouvette, C. 1999. Process of tomato root colonization by a pathogenic strain of Fusarium oxysporum f. sp. lycopersici in comparison with a non-pathogenic strain. New Phytol. 141:497-510.

Oliver, B. G., Panepinto, J. C., Askew, D. S., and Rhodes, J. C. 2002. cAMP alteration of growth rate of Aspergillus fumigatus and Aspergillus niger is carbon-source dependent. Microbiology 148:2627-2633.

Ospina-Giraldo, M., Mullins, E., and Kang, S. 2003. Loss of function of the Fusarium oxysporum $S N F 1$ gene reduces virulence on cabbage and Arabidopsis. Curr. Genet. 44:49-57.

Pan, X., and Heitman, J. 1999. Cyclic AMP-dependent protein kinase regulates pseudohyphal differentiation in Saccharomyces cerevisiae. Mol. Cell. Biol. 19:4874-4887.

Panorchan, P., Thompson, M. S., Davis, K. J., Tseng, Y., Konstantopoulos, K., and Wirtz, D. 2006. Single-molecule analysis of cadherin-mediated cell-cell adhesion. J. Cell Sci. 119:66-74.

Pareja-Jaime, Y., Martin-Urdiroz, M., Roncero, M. I. G., González-Reyes, J. A., and Roldán, M. D. C. R. 2010. Chitin synthase-deficient mutant of Fusarium oxysporum elicits tomato plant defence response and protects against wild-type infection. Mol. Plant Pathol. 11:479-493.

Pukkila-Worley, R., and Alspaugh, J. A. 2004. Cyclic AMP signaling in Cryptococcus neoformans. FEMS (Fed. Eur. Microbiol. Soc.) Yeast Res. 4:361-367.

Ramesh, M. A., Laidlaw, R. D., Dürrenberger, F., Orth, A. B., and Kronstad, J. W. 2001. The cAMP signal transduction pathway mediates resistance to dicarboximide and aromatic hydrocarbon fungicides in Ustilago maydis. Fungal Genet. Biol. 32:183-193.

Recorbet, G., and Alabouvette, C. 1997. Adhension of Fusarium oxysporum conidia to tomato roots. Lett. Appl. Microbiol. 25:375-379.

Regenfelder, E., Spellig, T., Hartmann, A., Lauenstein, S., Bölker, M., and Kahmann, R. 1997. G proteins in Ustilago maydis: Transmission of multiple signals? EMBO (Eur. Mol. Biol. Soc.) J. 16:1934-1942.

Rocha, C. R. C., Schroppel, K., Harcus, D., Marcil, A., Dignard, D., Taylor, B. N., Thomas, D. Y., Whiteway, M., and Leberer, E. 2001. Signaling through adenylyl cyclase is essential for hyphal growth and virulence in the pathogenic fungus Candida albicans. Mol. Biol. Cell 12:3631-3643.

Ruiz-Roldán, M. C., Maier, F. J., and Schäfer, W. 2001. PTK1, a mitogen- 
activated-protein kinase gene, is required for conidiation, appressorium formation, and pathogenicity of Pyrenophora teres on barley. Mol. Plant-Microbe Interact. 14:116-125.

Schumacher, J., Kokkelink, L., Huesmann, C., Jimenez-Teja, D., Collado, I. G., Barakat, R., Tudzynski, P., and Tudzynski, B. 2008. The cAMPdependent signaling pathway and its role in conidial germination, growth, and virulence of the gray mold Botrytis cinerea. Mol. Plant-Microbe Interact. 21:1443-1459.

Sengupta, N., Vinod, P. K., and Venkatesh, K. V. 2007. Crosstalk between cAMP-PKA and MAP kinase pathways is a key regulatory design necessary to regulate FLO11 expression. Biophys. Chem. 125:59-71.

Shimizu, K., and Keller, N. P. 2001. Genetic involvement of a cAMP-dependent protein kinase in a $\mathrm{G}$ protein signaling pathway regulating morphological and chemical transitions in Aspergillus nidulans. Genetics 157:591-600.

Shishido, M., Miwa, C., Usami, T., Amemiya, Y., and Johnson, K. B. 2005. Biological control efficiency of Fusarium wilt of tomato by nonpathogenic Fusarium oxysporum Fo-B2 in different environments. Phytopathology 95:1072-1080.

Stevens, M. M., Allen, S., Davies, M. C., Roberts, C. J., Schacht, E., Tendler, S. J. B., VanSteenkiste, S., and Williams, P. M. 2002. The development, characterization, and demonstration of a versatile immobilization strategy for biomolecular force measurements. Langmuir 18:6659-6665.

Stolz, M., Raiteri, R., Daniels, A. U., VanLandingham, M. R., Baschong, W., and Aebi, U. 2004. Dynamic elastic modulus of porcine articular cartilage determined at two different levels of tissue organization by indentation-type atomic force microscopy. Biophys. J. 86:3269-3283.

Stork, P. J. S., and Schmitt, J. M. 2002. Crosstalk between cAMP and MAP kinase signaling in the regulation of cell proliferation. Trends Cell Biol. 12:258-266.

$\mathrm{Su}$, B., and Karin, M. 1996. Mitogen-activated protein kinase cascades and regulation of gene expression. Curr. Opin. Immunol. 8:402-411.

Takano, Y., Komeda, K., Kojima, K., and Okuno, T. 2001. Proper regulation of cyclic AMP-dependent protein kinase is required for growth, conidiation, and appressorium function in the anthracnose fungus $\mathrm{Col}$ letotrichum lagenarium. Mol. Plant-Microbe Interact. 14:1149-1157.

Tamaki, H. 2007. Glucose-stimulated cAMP-protein kinase a pathway in yeast Saccharomyces cerevisiae. J. Biosci. Bioeng. 104:245-250.

Taylor, S. S., Radzio-Andzelm, E., Madhusudan, Cheng, X., Ten Eyck, L., and Narayana, N. 1999. Catalytic subunit of cyclic AMP-dependent protein kinase: Structure and dynamics of the active site cleft. Pharmacol. Ther. 82:133-141.

Taylor, S. S., Radzio-Andzelm, E., Ralph, A. B., and Edward, A. D. 2010. cAMP-Dependent Protein Kinase. Academic Press, San Diego, CA, U.S.A.

The Arabidopsis Genome Initiative. 2000. Analysis of the genome sequence of the flowering plant Arabidopsis thaliana. Nature 408:796-815.

Thevelein, J., Cauwenberg, L., Colombo, S., De Winde, J., Donation, M., Dumortier, F., Kraakman, L., Lemaire, K., Ma, P., Nauwelaers, D., Rolland, F., Teunissen, A., Van Dijck, P., Versele, M., Wera, S., and Winderickx, J. 2000. Nutrient-induced signal transduction through the protein kinase A pathway and its role in the control of metabolism, stress resistance, and growth in yeast. Enzyme Microb. Technol. 1:819825.

Thines, E., Weber, R. W. S., and Talbot, N. J. 2000. MAP kinase and protein kinase A-dependent mobilization of triacylglycerol and glycogen during appressorium turgor generation by Magnaporthe grisea. Plant Cell 12:1703-1718.

Tokiwa, G., Tyers, M., Vilpe, T., and Futcher, B. 1994. Inhibition of G1 cyclin activity by the Ras/cAMP pathway in yeast. Nature 371:342-345.

Tzima, A., Paplomatas, E. J., Rauyaree, P., and Kang, S. 2010. Roles of the catalytic subunit of cAMP-dependent protein kinase A in virulence and development of the soilborne plant pathogen Verticillium dahliae. Fungal Genet. Biol. 47:406-415.

Wang, G.-L., Valent, B., Ding, S., Zhou, X., Zhao, X., and Xu, J.-R. 2009. The PMK1 MAP Kinase Pathway and Infection-Related Morphogenesis. Springer, The Netherlands.

$\mathrm{Xu}$, J.-R., and Hamer, J. E. 1996. MAP kinase and cAMP siganling regulate infection structure formation and pathogenic growth the rice blast fungus Magnaporthe grisea. Genes Dev. 10:2696-2706.

Xu, J.-R., Urban, M., Sweigard, J. A., and Hamer, J. E. 1997. The CPKA gene of Magnaporthe grisea is essential for appressorial penetration. Mol. Plant-Microbe Interact. 10:187-194.

Yamauchi, J., Takayanagi, N., Komeda, K., Takano, Y., and Okuno, T. 2004. cAMP-PKA signaling regulates multiple steps of fungal infection cooperatively with Cmk1 MAP kinase in Colletotrichum lagenarium. Mol. Plant-Microbe Interact. 17:1355-1365.

Yang, Q., and Borkovich, K. A. 1999. Mutational activation of Gai causes uncontrolled proliferation of aerial hyphae and increased sensitivity to heat and oxidative stress in Neurospora crassa. Genetics 151:107-117.

Yang, Z., and Dickman, M. B. 1999. Colletotrichum trifolii mutants disrupted in the catalytic subunit of cAMP-dependent protein kinase are nonpathogenic. Mol. Plant-Microbe Interact. 12:430-439.

Yu, G., Li, J., and Young, D. 1994. The Schizosaccharomyces pombe pkal gene, encoding a homolog of cAMP-dependent protein kinase. Gene 151:215-220.

Yu, H.-Y., Seo, J.-A., Kim, J.-E., Han, K.-H., Shim, W.-B., Yun, S.-H., and Lee, Y.-W. 2008 Functional analyses of heterotrimeric G protein G $\alpha$ and G $\beta$ subunits in Gibberella zeae. Microbiology 154:392-401.

Zhao, X., Kim, Y., Park, G., and Xu, J.-R. 2005. A mitogen-activated protein kinase cascade regulating infection-related morphogenesis in Magnaporthe grisea. Plant Cell 17:1317-1329. 